\title{
The migration of the great snipe Gallinago media: intriguing variations on a grand theme
}

Åke Lindström ${ }^{1}$, Thomas Alerstam ${ }^{1}$, Peter Bahlenberg ${ }^{2}$, Robert Ekblom ${ }^{3}$, James W. Fox ${ }^{4}$, Johan Råghall ${ }^{2}$ and Raymond H. G. Klaassen ${ }^{5}$

${ }^{1}$ Department of Biology, Lund University, Ecology Building, SE-22362 Lund, Sweden

${ }^{2}$ Lake Ånnsjön Bird Observatory, Handöl 563, SE-83015 Duved, Sweden

${ }^{3}$ Department of Ecology and Genetics, Evolutionary Biology Centre, Uppsala University, Norbyvägen 18

D, SE-75236 Uppsala, Sweden

${ }^{4}$ British Antarctic Survey, Natural Environment Research Council, High Cross, Madingley Road, Cambridge CB3 OET, UK

${ }^{5}$ Conservation Ecology Group, GELIFES, University of Groningen, The Netherlands

Corresponding author: Åke Lindström, Department of Biology, Lund University, Ecology Building, SE22362 Lund, Sweden. E-mail: ake.lindstrom@biol.lu.se

Decision date: $24-$ Sep-2015

This article has been accepted for publication and undergone full peer review but has not been through the copyediting, typesetting, pagination and proofreading process, which may lead to differences between this version and the Version of Record. Please cite this article as doi: [10.1111/jav.00829]. 


\section{Abstract}

The migration of the great snipe Gallinago media was previously poorly known. Three tracks in 2010 suggested a remarkable migratory behaviour including long and fast overland non-stop flights (Klaassen et al. 2011). Here we present the migration pattern of Swedish male great snipes, based on 19 individuals tracked by light-level geolocators in four different years. About half of the birds made stopover(s) in northern Europe in early autumn. They left the breeding area 15 days earlier than those which flew directly to sub-Sahara, suggesting two distinct autumn migration strategies. The autumn trans-Sahara flights were on average $5500 \mathrm{~km}$ long, lasted $64 \mathrm{~h}$, and were flown at ground speeds of $25 \mathrm{~m} \mathrm{~s}^{-1}\left(90 \mathrm{~km} \mathrm{~h}^{-1}\right)$. The arrival in the Sahel zone of West Africa coincided with the wet season there, and the birds stayed for on average three weeks. The birds arrived at their wintering grounds around the lower stretches of the Congo River in late September and stayed for seven months. In spring the great snipes made trans-Sahara flights of similar length and speed as in autumn, but the remaining migration through eastern Europe was notably slow. All birds returned to the breeding grounds within one week around mid-May. The annual cycle was characterized by relaxed temporal synchronization between individuals during the autumn-winter period, with maximum variation at the arrival in the wintering area. Synchronization increased in spring, with minimum time variation at arrival in the breeding area. This suggests that arrival date in the breeding area is under strong stabilizing selection, while there is room for more flexibility in autumn and arrival to the wintering area. The details of the fast non-stop flights remain to be elucidated, but the identification of the main stopover and wintering areas is important for future conservation work on this red-listed bird species.

Keywords: Migration patterns; endurance exercise; geolocators; 


\section{Introduction}

It has long been known that many birds migrate vast distances across our planet. Our knowledge about

these migrations has grown gradually, mainly aided by technical developments such as bird ringing, radar, satellite tracking and geolocators (Alerstam 2006, Newton 2008). A huge step forward came in the early 1990's when it became possible to track the full annual migration of individual birds (Jouventin and Weimerskirch 1990, Berthold et al. 1992, Meyburg et al. 1995, Kjellén et al. 1997). Since then more and more studies have been published with year-around tracks of individual birds. This has resulted in important new knowledge about the within- and between-individual variation in spatial and temporal organisation of migration (Battley 2006, Stutchbury et al. 2008, Vardanis et al. 2011, Conklin et al. 2010, 2013, McKinnon et al. 2013, Hooijmeijer et al. 2013). Such basic information is pivotal to ultimately understand the main factors shaping migration strategies of birds, such as seasonal and spatial variation in climate and food abundance (Pearson and Backhurst 1976), avoidance of predators and pathogens (Gill et al. 2009), and generic weather (wind) patterns (Alerstam 1990).

The tracking of individual birds has also revealed more about their maximum physical performance, as shown by the length, duration and speed of the most extreme non-stop flights (Hedenström 2010). Based on aerodynamic theory, the maximum possible distances for birds in active flight in still air were for long predicted to be about 4000-5000 km, lasting up to four days (Pennycuick 1975, Alerstam 1990). Such distances and durations have now been proven to be underestimates, with distances of $7000-11000 \mathrm{~km}$ and durations of up to 9 days being recorded in several wader species (Gill et al. 2009, Minton et al. 2010, Tomkovich et al. 2013, Senner et al. 2014). In another wader species, the great snipe Gallinago media, surprisingly high average flight speeds have been recorded, up to $25-27 \mathrm{~m} \mathrm{~s}^{-1}$ (around $90 \mathrm{~km} \mathrm{~h}^{-1}$ ), speeds that seemingly were not the result of strong tailwind support (Klaassen et al. 2011).

The great snipe is a rare wader species breeding in northern Europe eastwards to River Yenisey in Russia (del Hoyo et al. 2006). A relatively small Scandinavian population is geographically, and genetically, separated from the birds further east in Europe (Ekblom and Carlsson 2007; Ekblom et al. 2010). The great snipe was formerly a common breeding bird over southern Scandinavia (Lindblad 1863), but the present breeding distribution is tightly connected to sloping fens at altitudes of $700-1100 \mathrm{~m}$ a.s.l. in 
the Fennoscandian mountains. In Sweden they breed north of $62^{\circ}$ (Ekblom and Carlsson 2007). In southern Sweden it occurs only scarcely on spring and autumn migration (SOF 2002). The great snipe is red-listed as "Near Threatened" both in Sweden and globally (Artdatabanken 2015, http://www.iucnredlist.org/).

Even the basics of great snipe migration were for a long time poorly known. Whereas it was indeed recognized that the European breeding birds mainly winter south of the Sahara, the actual winter quarters of the different European populations were not properly known (Glutz von Blotzheim et al. 1977, Cramp and Simmons 1983). As far as the Scandinavian birds are concerned, until recently only about 10 ringing recoveries existed of birds ringed at their Scandinavian breeding sites, none of which were from south of the Mediterranean Sea (Bakken et al. 2003, Fransson et al. 2008).

In contrast to the relatively poor knowledge of the migration through southern Europe to Africa even in present days, there are surprisingly many details known from Scandinavia from the 19th century, about migration timing (arrival and departure dates) and body mass for migratory flights. This is because the great snipe was much more common then, and in addition a very popular and easy quarry (Lindblad 1863, Barth 1881, Kolthoff 1901).

Three individual tracks based on light-level geolocators recently revealed a remarkable migratory behaviour of Scandinavian great snipes (Klaassen et al. 2011). In early autumn, the birds made long and fast non-stop flights directly from the breeding area in N Sweden (two birds) or from a stopover site in $\mathrm{S}$ Norway (one bird) to stopover sites south of the Sahara. These endurance flights were unexpected mainly because the flights were made over land and thus the birds seem to surpass favourable fuelling habitat in outhern Europe. All three birds wintered in the rainforest belt near the Equator. These exciting preliminary findings called for an in-depth study, and we now have data for 19 individual males collected in four different years. We use the timing and durations recorded for the different individuals, to test how temporally synchronized individuals are in various parts of the annual cycle, and to investigate how durations and timings of specific phases in the annual cycle affect subsequent events in the annual cycle (based on variation between individuals). Such information is important for understanding constraints and bottle-necks potentially affecting the birds during migration (Conklin et al. 2013, Senner et al. 2014). 
Combined with surveying available older information we provide a synthesis of the migration cycle of the great snipe, including the intriguing variation in geographic and temporal patterns.

\section{Material and methods}

\section{Field work}

Our study was conducted in the second half of May 2009-2014 near Storulvån, Jämtland, Sweden $\left(63^{\circ}\right.$ N, $12^{\circ} \mathrm{E}$ ), as a part of the activities of Lake Ånnsjön Bird Observatory. Over the six years, we visited in total eight different leks, but not all leks were visited every year. The initial focal lek (see Klaassen et al. 2011) was only studied in 2009-2010, as it was abandoned in 2011 for unknown reasons and never re-established. The number of leks visited increased over the study period, from three leks in 2009 to five leks in 2014.

Great snipes were caught in wader-mistnets placed in a horseshoe-formation around the lek (with the open end of the horseshoe pointing uphill). Nets were erected a few hours before midnight, and birds were captured during the darkest hours of the night (but note that it never gets completely dark at this northern latitude at this time of the year). Snipes were caught spontaneously when arriving at the lek, or during hourly net-check rounds when we flushed birds from the lek by entering the catching area from the open end of the horseshoe mistnet-formation. From 2013 and onwards we adopted a slightly different catching protocol in that nets were erected a few hours before midnight, but not opened until we presumed that all males had arrived at the lek (i.e. around midnight). This made catching more efficient and we avoided retrapping birds within a night.

Standard biometric measurements were collected, including wing length (maximum chord length of flattened and straightened wing), tarsus + toe (distance from the back of the tarsal joint to tip of longest toe nail), head length (distance from tip of bill to back of skull), bill length (distance from tip of bill to farthest point of exposed non-feathered culmen ridge), and tarsus (tarso-metatarsus, distance between the extreme bending points, as measured while holding foot and tibiotarsus perpendicular to the tarso-metatarsus). In addition, birds were weighed using a Pesola spring balance or an electronic balance, to the nearest gram. Birds were sexed on the basis of the combination of measurements (bill length, head length, body mass) and the extent of white on the outer tail feathers (cf. Höglund et al. 1990).

'This article is protected by copyright. All rights reserved.' 
In total, 70 light-level geolocators were fitted on male great snipes in 2009-2013 (Table 1).

Different geolocator models from different manufacturers (British Antarctic Survey [BAS], Cambridge, UK, and Migrate Technology Ltd. [MT], Cambridge, UK) were used in different years, but all models weighed less than 1.1 gram. Geolocators were attached with the light-sensor pointing downwards to the metal ring or to a plastic colour ring sitting on the tibia (tibiotarsus; i.e. above the "knee", see Klaassen et al. 2011). The geolocator was either strapped to the ring using a cable-tie (with a small piece of $1 \mathrm{~mm}$ thick rubber or self-amalgamating tape in between the cable-tie and the ring/geolocator) or knotted to the ring using $1 \mathrm{~mm}$ wide polyester braided self-string (British Trust for Ornithology, BTO, Thetford, UK). From 2011 and onwards, a colour ring was placed underneath the ring supporting the geolocator to slightly raise the geolocator in order to prevent the device pushing on the tarsus when the leg is bent (Johnson et al. 2011). All geolocators except two (one in 2012 and one in 2013) were attached to males. When choosing which individuals to fit geolocators on, we selected for males already ringed in previous years ('ringing controls'), assuming that the fact they had already successfully carried out at least one return migration would increase the chance to get the geolocator back. Of the 70 birds given geolocators, 20 were birds that were ringed in a previous year $(29 \%)$.

In total, 22 geolocators were recovered: 20 after the first year of geolocator attachment, one after two years and one after three years. The latter geolocator unfortunately contained no information at all when retrieved. Out of the 22 geolocators recovered, 15 were recovered at the same lek as where the geolocator had been attached. Return rates of great snipes varied between years, in which 2013 was a melatively poor year ( $20 \%$ returns) and 2012 a relatively good year (55-80\% returns, Table 1$)$. The return rate of geolocator birds (22 out of 70; 31\%) was not different from that of males handled during ringing sessions but not deployed with geolocators $\left(24 / 78 ; 31 \%, \chi_{(1)}^{2}=0.0, p=0.99\right.$, Table 1). In the latter group, 13 out of 78 were controls from previous years $(17 \%)$.

However, this analysis includes two seasons in which we failed to retrieve geolocators. First, in 2011, we did not retrieve any geolocators because the focal lek had been abandoned (as mentioned above). Second, three of the 16 birds that got a geolocator in 2012 returned, but unfortunately they all had dropped their geolocator. If we exclude these two deviating seasons (loss of the main lek, and poor attachment of 
loggers, respectively), the return rate of geolocator birds $(22 / 45 ; 49 \%)$ was not significantly different from those with no geolocators $\left(13 / 34 ; 38 \%, \chi_{(1)}^{2}=0.51, p=0.47\right)$. For the birds handled in 2009, 2011 and 2013, the return rate of geolocator birds was numerically higher for ringing controls $(7 / 9 ; 78 \%)$ than for birds handled for the first time $(15 / 36 ; 42 \%)$, but this difference was not statistically significant $\left(\chi_{(1)}^{2}=2.45\right.$, $\mathrm{p}=0.12)$. Of the birds that did not receive geolocators, too few already ringed birds were handled $(\mathrm{n}=3)$ to allow the corresponding test to be carried out. If we only look at birds handled for the first time, the return rate was very similar between the birds that got a geolocator $(15 / 36,42 \%)$ and those that did not carry a geolocator $\left(13 / 34,38 \%, \chi_{(1)}^{2}=0.002, \mathrm{p}=0.96\right)$. Accordingly, there is no reason to believe that the geolocators caused a decline in the between-year return rate of great snipes.

\section{Geolocator data analysis}

Different geolocator models were used in this study, with different light sensors (from dim-light measurements to full light range measurements) and different temporal resolutions of light measurements (light level was measured every minute, subsequently maximum light values were stored per 2 to 10 minute periods). By adopting the 'threshold method' (see Lisovski et al. 2012) to analyse the data, different datatypes could be analysed in a comparable way, where the sun angle corresponding to the arbitrarily chosen threshold value (see below) was determined for each individual geolocator.

After logger retrieval, data were downloaded within a day, and the time was corrected for clock drift. Devices with drained batteries were sent to the manufacturer to extract data. These data were not orrected for clock drift, but there was no indication of significant clock drift (no gradual longitudinal movement at stationary sites) and the clock drift for fully functioning geolocators was small.

Subsequently, data was loaded in BASTrak TransEdit (BAS) and inspected for false twilight events (for example shading during the day or short spikes of light during the night). After removing false twilights, times of sunrise and sunset were extracted, using a single light threshold value of 5. Locations were calculated using BASTrak Locator (BAS), in which latitude is calculated from the length of the solar day (or night) and longitude from the time of local solar noon (or midnight).

'This article is protected by copyright. All rights reserved.' 
The sun angle corresponding to a light threshold light value of 5 was found by Hill-Ekstrom calibration (Lisovski et al. 2012). Hill-Ekstrom calibration is based on three basic principles in light-level geolocation (Hill and Braun 2001, Ekstrom 2004, see also Supplement Fig. S1). (1) The error in latitude increases with an increasing mismatch between the used sun angle and the true sun angle corresponding to the chosen light threshold, in which the latitude is underestimated when a too small sun angle is used, and overestimated when a too large sun angle is used (or vice versa). (2) An error resulting from such a mismatch in sun angles is amplified closer to equinox. (3) The sign of the error reverses at equinox, meaning that latitude is overestimated before the equinox and underestimated after the equinox (or vice versa, see Supplement Fig. S1).

We inspected patterns of estimates of latitude over time for a range of sun angles (at steps of 0.5 degrees) in order to find the sun angle that (1) minimized the amplification of the error in latitude close to equinoxes, and at the same time (2) for which the estimate for latitude was similar before and after equinox (see Supplement Fig. S2). This 'best sun angle' was subsequently used to calculate positions throughout the rest of the year. Separate calibrations were conducted for autumn (based on the autumn equinox) and for spring (based on the spring equinox). An important assumption for Hill-Ekstrom calibration is that the bird is stationary during the equinox, otherwise the estimate for latitude could differ before and after equinox due to the movement. In the few cases where the great snipes moved during the equinox, as could be inferred from changes in longitude (see below), the 'best sun angle' was found by solely judging the amplification in the error in latitude for the period the bird was stationary. For more information about alibration issues in general and Hill-Ekstrom calibration in particular, see the Supplementary Information and Lisovski et al. (2012).

After the Hill-Ekstrom calibration, tracks were annotated, in which we distinguished between stationary periods and migratory flights by inspecting patterns of latitude and longitude over time. In great snipes, movements generally are long and fast, resulting in prominent shifts in latitude and longitude during migratory flights. Only for spring migration through Europe, it was difficult to distinguish between stopovers and flights as the birds seem to make short daily movements. For the trans-Sahara non-stop 
flights, data was smoothed twice following Pütz (2002), giving estimates for noon and midnight positions, which defined 12h flight segments (see Supplement Fig. S3).

Some of the loggers [MT] retrieved in 2012-2014 recorded full light range data, which allowed us to verify our track annotations. At the breeding or European stopover areas (see results) in late summer, daytime light data contained many 'false nights' (i.e. short periods of darkness), possibly because the birds visited relatively dark habitats during the day or because the logger was regularly covered by feathers (for example when the leg with the logger is lifted and folded under the belly feathers when resting). This pattern changed very prominently when the birds had embarked on their long south-bound flights (see Supplement Fig. S4) as judged from sudden changes in latitude and longitude. No more false dark periods occurred during daytime, suggesting significantly less shading. Upon arrival in Africa, light data remained distinctly clean (i.e. relatively few false nights occurred during the day), suggesting a change in habitat or behaviour and that the birds are using very open habitats in Africa. Accordingly, raw light data could be used to help to decide when the individual had departed from the breeding or European stopover area, and when the bird had arrived to the sub-Saharan stopover area (see Supplement Fig. S4), although the latter seems only possible for loggers recording full light range data.

\section{Analyses of temporal variation and correlations}

One individual (ring \#5116319) was tracked for three seasons: 2009/2010 (whole year), 2011/2012 (whole year) and 2012/2013 (autumn and winter only). The second year and third autumn migration of this bird is ot included in the analysis of average migration performance of the population, but is referred to separately. When comparing the dates for the three autumn migrations of this individual, one day was added to the dates of year 2012, to correct for 2012 being a leap year.

Variation (standard deviation) in dates were calculated for five key events in the annual cycle, (1) departure from breeding area, (2) arrival in the Sahel region south of Sahara, (3) arrival in the equatorial winter quarters, (4) departure from the wintering area and (5) spring arrival in the breeding area (data available for 12-19 individuals). The null hypothesis that temporal scatter was the same for all events was tested by pairwise F-ratio tests (Sokal and Rohlf 1995).

'This article is protected by copyright. All rights reserved.' 
Relationships between successive dates and durations in the annual cycle were tested in linear mixed models (SPSS Statistics v. 22, IBM), where the dependent date/duration was regressed on the preceding date/duration (covariate) with year as random factor (to correct for pseudoreplication by year). Dates for the five key events described above were used in these analyses along with the durations of four intervening periods, (a) duration of autumn stopover in Europe (outside the breeding area), (b) duration of autumn stopover in the Sahel region, (c) duration of the winter period and (d) duration of the spring stopover in Europe. Sample size ranged from 12 to 19 in these mixed model linear regression analyses. In addition, the possible effects of the durations of the long non-stop autumn and spring flights on autumn stopover duration in Sahel and spring stopover duration in Europe, respectively, were tested in linear mixed models with year as random factor.

\section{Results}

Complete annual tracks were retrieved for 3 birds in 2009/2010 (Klaassen et al. 2011), 6 birds in 2011/2012 and 4 birds in 2013/2014. Tracks giving autumn migration plus wintering area position were retrieved for 3 birds in 2011/2012, 1 in 2012/2013, and 4 in 2013/2014. One bird in the latter group could be tracked until 20 April. Accordingly, we have information on 21 complete autumn migrations and wintering area positions (including three from individual \#5116319), 14 from the early phase of spring migration (two from \#5116319), and 13 complete spring migrations (two from \#5116319; Table 1, Fig. 1).

\section{Departure from the breeding grounds}

The average departure date from the breeding grounds was 17 August $(\mathrm{SD}=10.6 \mathrm{~d}$, range: 4 August -9 September, $\mathrm{n}=19$ ), but the dates differed depending on how the autumn migration was carried out. The nine birds that made stopovers elsewhere in Europe before the trans-Saharan flight departed on average 15 days earlier from the breeding grounds than those 10 birds that embarked on their trans-Saharan flight directly from the breeding grounds (average 9 August, $\mathrm{SD}=8.7 \mathrm{~d}$, range: 4 August-1 September vs. average 24 August, $\mathrm{SD}=6.2 \mathrm{~d}$, range: 17 August-9 September; $\mathrm{t}$-test, $\mathrm{t}_{17}=4.34$, $\mathrm{p}<0.001$, Fig. 2 ). 
One bird (\#5145967) departed unusually late for a bird making a stopover in Europe (Fig. 2). In addition, this was the only bird stopping in southern Europe (border region Italy/France). Geolocator data indicated that this individual interrupted its non-stop flight, including a reverse migration over the Mediterranean Sea (data not shown). Hence, its stopover possibly should be regarded as an emergency stop rather than a planned stopover for fuelling. If we exclude this bird that most likely interrupted a transSahara flight, the departure dates of great snipes that make a stopover in Europe is on average 7 August $(\mathrm{SD}=2.5 \mathrm{~d}$, range: $4-11$ August $)$.

The bird that by far was the last to leave the breeding grounds, on 9 September, was the only bird that flew non-stop directly to the wintering grounds (\#5145923). Bird \#5116319 left the breeding grounds on 12, 23 and 22 August in the three years, respectively, and made a stopover in Europe the first year only (Fig. 2). 


\section{Autumn stopover in northern Europe}

Nine birds clearly made one or more stopovers within Europe before they embarked on their trans-Saharan flight. Eight of them stopped in northern Europe, one of which later seemed to make a regular stop in northern Africa. Only one bird made a stopover in southern Europe (the above-mentioned individual that may have made an emergency stop, \#5145967). The total stopover time in Europe/northern Africa for the eight birds with "regular" stopovers before crossing the Sahara was on average $18.7 \mathrm{~d}$ ( $\mathrm{SD}=6.0$, range: 10.5-27.0). The northern Europe sites from where they later departed on a trans-Saharan flight were mainly located in southern Norway, southern Sweden, Denmark, eastern Germany and western Poland. Bird \#5116319 made a European stopover in 2009 (lasting 14 d), but not in 2011 or 2012.

\section{Autumn trans-Sahara flights}

The average departure date for all trans-Saharan flights was 27 August ( $\mathrm{SD}=7.7 \mathrm{~d}$, range: 17 August-19 September, $\mathrm{n}=19)$, with 14 of the birds departing 22-31 August. On average the flights lasted $60.1 \mathrm{~h}(\mathrm{SD}=$ 15.7, range: $24.3-83.7, \mathrm{n}=19)$, covered a distance of $5277 \mathrm{~km}(\mathrm{SD}=1093$, range: $2449-6894, \mathrm{n}=19)$, and were flown at an average (ground) speed of $25.3 \mathrm{~m} \mathrm{~s}^{-1}(\mathrm{SD}=5.1$, range: $14.6-33.3, \mathrm{n}=19)$. If we exclude the two birds that made stopovers in southern Europe/northern Africa, and thus deviated from the general pattern, the corresponding averages are $63.6 \mathrm{~h}, 5501 \mathrm{~km}$, and $24.7 \mathrm{~m} \mathrm{~s}^{-1}$. The latter is equal to $88.9 \mathrm{~km} \mathrm{~h}^{-1}$.

For the eight birds that had stopovers in Europe before they flew across the Sahara, the trans-Sahara flights lasted on average $53.7 \mathrm{~h}$ ( $\mathrm{SD}=15.1$, range: $24.3-72.0)$, covered a distance of $4684 \mathrm{~km}(\mathrm{SD}=1165$, ange: 2449-6225), and were flown at an average (ground) speed of $25.1 \mathrm{~m} \mathrm{~s}^{-1}(\mathrm{SD}=5.3$, range: 14.629.5). The corresponding averages for the ten birds with a successful trans-Sahara flight commencing at the breeding grounds were $67.5 \mathrm{~h}(\mathrm{SD}=12.5$, range: 37.4-83.7), $5849 \mathrm{~km}$ ( $\mathrm{SD}=742$, range: 4483-6894), and $24.8 \mathrm{~m} \mathrm{~s}^{-1}(\mathrm{SD}=4.8$, range: $19.0-33.3)$. Whereas the length and duration of the flights were significantly longer in the second group $\left(\mathrm{t}_{(16)}=2.1, \mathrm{p}=0.049\right.$ and $\mathrm{t}_{(16)}=2.6, \mathrm{p}=0.020$, respectively), ground speeds were not $\left(\mathrm{t}_{(16)}=0.1, \mathrm{p}=0.90\right)$.

Bird \#5116319 departed on his trans-Sahara flights 26, 23 and 22 August in the three years, respectively, with flight durations of $47.6,61.1$ and $71.8 \mathrm{~h}$, distances of 4623,5582 and $5522 \mathrm{~km}$, and 
speeds of 27.0, 26.7 and $21.4 \mathrm{~m} \mathrm{~s}^{-1}$. One of the 19 birds did not stop at all south of the Sahara, but flew directly from the breeding grounds to the wintering grounds $\left(60 \mathrm{~h}, 6900 \mathrm{~km}\right.$ and $\left.31.9 \mathrm{~m} \mathrm{~s}^{-1}\right)$.

\section{Sub-Saharan stopover}

In total 18 of the 19 birds made one or two stopovers south of the Sahara, apparently between 5 and $19{ }^{\circ} \mathrm{N}$. About half of the birds appeared to have stopped in Niger and Chad north of $13^{\circ} \mathrm{N}$, that is, in southern Sahara. However, these stops in the Sahara must be interpreted with caution since they were carried out at dates within 2-4 weeks of autumn equinox, a period when latitude is becoming increasingly hard to determine accurately. Although stopovers in oases cannot be ruled out, it is more likely that the birds actually stopped just south of the desert.

The longitudes of the stopover sites, a much more accurate measure, were fairly evenly spread within 0-16 ${ }^{\circ}$ E. If we assume that all stopovers to have been carried out south of the Sahara, this corresponds to a belt covering Ghana, Burkina Faso, Benin, Nigeria, northernmost Cameroon and southernmost Chad, where northern Nigeria stands out as a key area.

The birds arrived at the stopover sites south of the Sahara on average on 29 August ( $\mathrm{SD}=7.1 \mathrm{~d}$, range: 20 August-20 September, $\mathrm{n}=18$ ). The total sub-Saharan stopover time was on average 23.3 days (SD $=10.7$, range: $10.5-51.0, \mathrm{n}=18)$. Six of the birds made two stopovers in this period, and interestingly, in all cases the second site was situated to the west of the first site. Bird \#5116319 arrived on the 28, 25 and 25 August respectively, and made one stopover each of the years, lasting 13.0, 8.5 and 12.5 days respectively.

The presence of great snipes on their sub-Saharan stopover sites peaked in early September. Over a short period, 1-8 September, more than $75 \%$ of the 18 geolocator birds were present (had they been there the same year, Fig. 3). The birds departed towards their final wintering grounds on average on 21 September $(\mathrm{SD}=13.8 \mathrm{~d}$, range: 4 September-19 October, $\mathrm{n}=18)$.

\section{Main wintering grounds}

The great snipes had on average reached their final winter destination already by 22 September (SD $14.1 \mathrm{~d}$, range: 4 September-22 October, $n=19$ ), on average 35.4 days after departure from the breeding grounds 
(range 2.5-77.4 days). Bird \# 5116319 arrived to its wintering grounds on 12, 5 and 8 September, respectively. Wintering sites were concentrated to an area around the Equator, ranging $5^{\circ} \mathrm{S}-4^{\circ} \mathrm{N}$ and 14 $19^{\circ} \mathrm{E}$, with one bird further west at $11^{\circ} \mathrm{E}$ and two birds further east at $24^{\circ} \mathrm{E}$. The main area corresponds to eastern Gabon, Congo, and the western half of the Democratic Republic of Congo, roughly coinciding with the lower stretches of the Congo River. There were no indications of longer movements within the winter quarters.

The average spring departure date for the 13 birds we had data on was 18 April ( $\mathrm{SD}=6.1 \mathrm{~d}$, range: 3-28 April). Accordingly, the birds stayed in their winter quarters for about 7 months. Bird \#5116319 departed on 26 and 24 April, respectively (note that no data was obtained for this individual for spring migration in 2012/2013).

\section{Spring migration across the Sahara}

Following their departure from the winter quarters in mid-April, the birds flew non-stop on average for 63.3 $\mathrm{h}(\mathrm{SD}=12.5$, range: $47.3-84.0, \mathrm{n}=13)$, covered a distance of $5224 \mathrm{~km}(\mathrm{SD}=479$, range: $4279-5892$, $\mathrm{n}=13$ ), at an average (ground) speed of $23.6 \mathrm{~m} \mathrm{~s}^{-1}(\mathrm{SD}=4.0$, range: $17.2-29.9, \mathrm{n}=13)$. None of the birds made a stopover in the first $1500 \mathrm{~km}$ of the spring migration when travelling over benign habitat south of the Sahara. Bird \#5116319 departed on his trans-Sahara flights 26 and 24 April in the two years, with flight durations of 48.0 and $59.4 \mathrm{~h}$, distances of 4279 and $5347 \mathrm{~km}$, and speeds of 24.7 and $25.0 \mathrm{~m} \mathrm{~s}^{-1}$.

\section{Spring migration through eastern Europe to the breeding grounds}

The 13 birds arrived in Europe on average on 20 April (SD 6.1 d, range: 7 April-1 May, n=13). Bird \#5116319 arrived on 28 and 26 April, respectively. During the migration northward within Europe the birds clearly shifted to a strategy of many short flights and many short stopovers. Following their arrival to southeast Europe, from Italy in the west to Ukraine in the east, there was a gradual, relatively steady, northward movement. Given the low precision of the geolocator data it is for this period difficult to determine specific stopover sites. The final $2000 \mathrm{~km}$ of spring migration can most likely be described as a slow continuous movement back to the breeding grounds. On average the birds used 25.7 days within 
Europe in spring (SD $7.6 \mathrm{~d}$, range: $16.0-45.0, \mathrm{n}=12$ ), which is equal to an average migration speed of about $80 \mathrm{~km} \mathrm{~d}^{-1}$. With an approximate flight (ground) speed of $90 \mathrm{~km} \mathrm{~h}^{-1}$, this is equivalent to an average of less than $1 \mathrm{~h}$ of flight per day. All 13 birds arrived to the breeding grounds within a seven day period, on average on 14 May ( $\mathrm{SD}=2.2 \mathrm{~d}$, range: 11-18 May). Bird \#5116319 arrived at the breeding grounds on 12 and 14 May, respectively.

\section{Temporal variation of the different migration phases}

The variation in timing between individuals differed significantly between different phases of the annual cycle (Fig. 4). It was maximal at the arrival in the wintering area ( $\mathrm{SD}=14.1 \mathrm{~d}$, range $48 \mathrm{~d}, \mathrm{n}=19$ ), whereas the individuals were most synchronized at the arrival in the breeding area $(\mathrm{SD}=2.2 \mathrm{~d}$, range $7.5 \mathrm{~d}, \mathrm{n}=12$ ). The standard deviation in timing increased significantly from the arrival in Sahel to the arrival in the wintering area $\left(\mathrm{F}_{17,18}=3.95, \mathrm{p}<0.01\right)$, while it subsequently decreased significantly for the succeeding departure from the wintering area $\left(\mathrm{F}_{18,12}=5.29, \mathrm{p}<0.01\right)$ and arrival in breeding area $(\mathrm{F} 12,11=8.05, \mathrm{p}<0.01)$, respectively (Fig. 4).

A flow chart of regression coefficients between succeeding timing events and durations in the annual cycle of the great snipes revealed several significant positive as well as negative relationships (Fig. 5). Positive regression coefficients indicate that a time difference at one stage in the annual cycle is transferred to the next stage and that an extended stationary period leads to a delay in the succeeding departure or arrival timing. A regression coefficient close to unity shows that the time effect is close to one ay postponement of the target date per day of increase in preceding date or period. Negative regression coefficients indicates synchronizing effects where a delay will be associated with reduced duration of the succeeding stationary period (with regression coefficient close to -1 showing a reduction in duration that corresponds to the delay in the starting date for that period).

Arrival date in the wintering area showed a strong positive regression coefficient in relation to the preceding arrival date in the Sahel region as well as to the duration of the Sahel stopover period (Fig. 5, Fig. 6a). Thus, individuals arriving late in the Sahel region were still correspondingly late in their arrival in the wintering area. Furthermore, the variation in the Sahel stopover duration (which was not correlated with 
arrival in Sahel) was directly transferred to the arrival date in the wintering area, causing this event to show the maximal temporal variation during the annual cycle (Fig. 4).

The Sahel stopover period was exceptional in that it was independent of the arrival date in Sahel, while the other three main stationary periods showed clearly negative regressions coefficients (close to -1) in relation to the preceding date. Hence, autumn stopover in Europe was primarily made by those individuals that departed early from the breeding area, while individuals departing later were more prone to fly directly to Africa without stopover in Europe (Fig. 2). Similarly, the duration of the winter period was shorter for the birds arriving late in the wintering area (Fig. 6b) leading to increased synchronization (Fig. 4). A further increase in synchronization (Fig. 4) resulted from a shorter spring stopover period in Europe for birds that departed late from the wintering area (Fig 6c). Correlation analyses showed that there were significant correlations (positive or negative) only between successive timing events and durations (as shown in Fig. 5) and not between more distant timing events or durations in the annual cycle.

The durations of the long non-stop flights during autumn and spring did not have any significant effects on the succeeding stopover durations in Sahel and Europe, respectively, according to the mixed model analyses $(\mathrm{p}>0.1)$.

\section{Discussion}

The use of geolocators in this study has provided entirely new knowledge about the migration strategy and winter distribution of Swedish male great snipes, which in many aspects are much different from what has heen assumed (Nilsson 1858, Lundblad 1863, Barth 1881, Kolthoff 1901, Panchenko 1985, Bakken et al. 2003, Bønløkke et al. 2006, Fransson et al. 2008, Delany et al. 2009, Saurola et al. 2013). Below we address the various stages of the great snipe migration scheme and end with discussing the overall variation in migration timing between individuals. The data now available do not only confirm that great snipes have a remarkable migration pattern with their long and fast overland non-stop flights (Klaassen et al. 2011), but should also be of importance from a conservation aspect for this red-listed species, as it enables conservation efforts to be directed not only towards the breeding grounds but also towards important staging sites and wintering localities.

'This article is protected by copyright. All rights reserved.' 


\section{Departure from the breeding grounds}

There seem to be two distinct (maybe even three) autumn migration strategies. One is to depart in the first half of August and to make one or several stopovers in northern Europe before leaving for Africa. The other strategy is to depart on the trans-Sahara flight directly from the breeding grounds and make a first landing in the Sahel. The bird tracked in three autumns used both strategies, so clearly the decision can be different in different years within individuals. The fact that the birds making a stopover in northern Europe left the breeding area about 15 days earlier than the birds that flew non-stop to Africa directly from the breeding area, strongly suggests that to leave the breeding grounds early in August and make stopovers in northern Europe must be the result of a decision taken well ahead of the long non-stop flight. That is, the stopovers in northern Europe do not seem to be emergency stops as a result of encountering adverse weather (wind) conditions, which seems for example to be the case for the spring stopovers in France of red knots Calidris canutus migrating from Mauretania to the Wadden Sea (Shamoun-Baranes et al. 2010).

One can only speculate about the factors determining whether the birds make a stopover in northern Europe or make a non-stop flight from the breeding site. Possibly the birds judge their own capacity for a long flight in late summer and then decide whether they first must move south to shorten the subsequent trans-Sahara flight. Another hypothesis may be that the strategy is related to age, with older and more experienced birds making the direct flight to the Sahel. Or does the decision depend mainly on the conditions on the breeding grounds? If feeding conditions and weather are good, does it pay to stay in potentially safer conditions in the mountains for fattening up? It should be mentioned in this context that in ll the seasons we obtained several tracks we observed both strategies. Finally, a single bird seems to have flown directly from the breeding to the wintering grounds. This may constitute a third and rare strategy, but also this aspect of the departure decision remains to be investigated.

Three distinct migration strategies have been described for adult continental black-tailed godwits Limosa limosa, migrating between breeding sites in the Netherlands and wintering in the Mediterranean basin or in West Africa, but as for our great snipes, the underlying causes are yet unknown (Hooijmeijer et al. 2013).Kolthoff (1901) reported, based on 300 great snipes shot by himself (!), that "the adult birds leave the breeding grounds in Jämtland already in mid-August, leaving only few adults behind in September”. 
We visited our study site in Jämtland on 21-25 August in 2011, which from our first geolocator birds we knew was within the main departure period for the non-stop flights. At and around the leks we flushed several great snipes. Clearly there were many birds still present near the leks in the main departure period, but since we were not able to trap any birds we know neither the age, sex nor body mass of the birds present. Kolthoff (1901) reported that birds present later on the breeding grounds in Jämtland (in September) were mainly juveniles.

Barth (1881) reports from the autumn hunt in southern Norway that birds are indeed shot at their breeding quarters up in the mountains, but the main hunt was when they started to appear in the lowlands. This suggests that some individuals make stopovers away from, but still near, their breeding quarters. They then "become so fat that the whole body is completely covered by a thick layer of fat, causing the skin to be so stretched that it bursts when the bird falls to the ground after being shot, and the feathers get covered by liquid oil" (our translation). The birds were reported to regularly weigh 235-250 g, and "even up to 265 g" and at the same time "the flight agility is drastically reduced" (Barth 1881). Lindblad (1863) stated that a fat bird weighed $210 \mathrm{~g}$. The highest body masses reported by Cramp and Simmons (1983) from various sites in northern Europe in autumn are $260 \mathrm{~g}$ (Norway), $225 \mathrm{~g}$ (Middle Volga, Russia), and $227 \mathrm{~g}$ (The Netherlands, [juveniles]).

Assuming a lean body mass (LBM) of about $160 \mathrm{~g}$ in males and $190 \mathrm{~g}$ in females (own observations at the lek in late May), the maximum masses recorded in the literature are surprisingly small for a bird bound for a non-stop flight of 5000-7000 km. A $260 \mathrm{~g}$ bird would have a fuel load of $62.5 \%$ above LBM if male and only $27 \%$ above LBM if a female (which indeed is the most likely sex of the heaviest birds). In species carrying out very long flights, such as bar-tailed godwits Limosa lapponica and sharp-tailed sandpipers Calidris acuminate that fly 8000-10000 km across the Pacific, some individuals are known to add fuel to more than $100 \%$ above LBM (Gill et al. 2009, Lindström et al. 2011). Either the really heaviest great snipes were rarely (if ever) shot or seen, or the flight energy budget of the great snipes is extremely efficient (i.e. the long flights are carried out on relatively small fuel reserves). It should be noted that on our brief visit to Jämtland on 21-25 August 2011, none of the flushed birds gave an especially heavy impression, suggesting that the birds are not grossly fat at departure. Alternatively, they were juvenile birds 
whose migration strategy may be different from that of adults. There is clearly a strong need for more body mass data from the period just before departure.

\section{Autumn stopover in northern Europe}

Around half of our birds made at least one stop outside the breeding area, but still in northern Europe, before embarking on the long non-stop flight. Of course, the birds we presume have migrated directly from the breeding area may have made smaller movements outside the summer territory before the long flight, but if so they were so short that they were not detectable with geolocator data. Based on observations in Norway, Barth (1881) concluded that autumn migration is carried out in small daily hops, since new birds arrived to a given site every day during early autumn migration (because all birds were shot the day before), and "the same holds for, as far as we can tell, the whole migration to and from the wintering grounds". Whereas the first conclusion may still be true, the last certainly is not.

In Denmark, great snipes are reported in low numbers in August-October, with a clear peak in the second half of August (Meltofte 1993). Meltofte suggested that a rather large part of the great snipes of Norway and Sweden may stop and fuel up in the meadows of Denmark, before they embark on a fast and direct flight to Africa south of the Sahara. We could only assign one bird to a stopover in Denmark, but again, due to the precision of the geolocators we may have missed some. Nevertheless, Meltofte (1993) was certainly right about the long flights.

Only a minority of our birds ( $21 \%)$ made an autumn stopover in continental Europe. This may xplain why relatively few great snipes are seen in western, central and southern Europe (Glutz von Blotzheim et al. 1977, Cramp 1983, Massoli-Novelli 1988b). It may also explain why the autumn migration of Fennoscandian birds by some has been suggested to run through eastern Europe, where more birds are reported in autumn (Lundblad 1863, Massoli-Novelli 1988b, but see Cramp and Simmons 1983). The latter birds, however, are more likely to be of eastern European origin. Glutz von Blotzheim et al. (1977) concluded that only little was known about the migration through western, central and southern Europe, and that possibly more or less regularly a few individuals would overfly several countries. Our data show that overflying southern Europe is indeed the main strategy of Scandinavian birds.

'This article is protected by copyright. All rights reserved.' 


\section{Autumn trans-Sahara flights}

Most of our birds made long and fast non-stop flights from northern Europe to sub-Saharan Africa, confirming our initial findings from three birds (Klaassen et al. 2011). Indeed, the ground speeds of our snipes (mean $25.3 \mathrm{~m} \mathrm{~s}^{-1}$, range 14.6-33.3) were substantially higher than those recorded for other shorebird species during similar non-stop flights over long distances (7.4-20.6 $\mathrm{m} \mathrm{s}^{-1}$, Gill et al. 2009, Minton et al. 2010, Niles et al. 2010, Johnson et al. 2012, Tomkovich et al. 2013). We have not analysed the wind conditions for all the present flights, but Klaassen et al. (2011) found for the first three birds that the high speeds most likely were not the result of strong tail winds. The intriguingly fast flights of the great snipes await more detailed studies, but more accurate registrations of the flights, preferably including information about altitude, will be needed to really be able to determine how the high ground speeds arise (e.g. McLaren et al. 2014), and how the snipes deal with and are affected by varying wind conditions.

\section{Sub-saharan stopover}

All but one of the 19 males made a sub-Saharan stopover, which on average lasted three weeks (Fig. 3). Massoli-Novelli (1988b) called the great snipe a "rain bird" because it moves into grassy areas south of the Sahara just after the rains have fallen there. He identified three areas in Africa with more than $1000 \mathrm{~mm}$ rain in July-September: Guinea-Ivory Coast, Nigeria-Cameroon and Ethiopia. Salvan (1968) reported from southernmost Chad that great snipes "are not rare in rice fields near Doba, after 15 August, till end of September". In coastal Benin, adult male great snipes start arriving in the second half of August, ahead of adult females and juveniles (Devort and Paloc 1992, Debayle 2003). In Nigeria, the great snipe "is most numerous on autumn passage, late August to October” (Elgood 1994). On the Jos Plateau in central Nigeria, great snipes have arrived from early August onwards also in the last 10 years, with a peak in numbers in early September with some birds still present in October. The birds are mainly found in very wet grasslands (Ulf Ottosson, pers. comm.). 
Particularly high densities of great snipes in autumn have been reported from Ethiopia, East Africa. These birds start to arrive in August, with peak densities in September (densities of 1300 birds per km² were estimated on flooded grasslands) and an almost complete exodus in mid-October (Massoli-Novelli 1988b). Hence, there seems to be a general pattern of autumn appearance in sub-Saharan African. The general lack of great snipes in Italy in autumn led Massoli-Novelli (1988a) to assume that the Scandinavian birds must fly elsewhere, probably more to the east, and therefore that the birds in Ethiopia included the Fennoscandian population. The geolocator tracks have now revealed that the snipes simply overfly Italy in autumn, and it is unlikely that the birds in Ethiopia include Scandinavian breeding birds.

What do the adult male great snipes do during their three week stay in the Sahel zone? Data from adult males shot in coastal Benin in late August-early September show that they arrive with a suspended primary moult, i.e. 4-6 primaries have already been replaced on the breeding grounds. The flight feather moult is resumed immediately upon arrival (Devort and Paloc 1992, Debayle 2003). It is unlikely that the great snipes can finalize both primary and secondary moult in only three weeks. In early October, when most of our geolocator birds had left for their wintering area, the birds in Benin were still all in active flight feather moult. The most likely scenario is therefore that our male birds made the final flight yet again in suspended flight feather moult (or maybe even in active moult), to be finalized in the winter quarters (Debayle 2003). Nevertheless, the need (or urge) to moult flight feathers, most likely under favourable conditions, may explain why the stopover period in Sahel is the only annual cycle event whose length is independent of its start (i.e. the arrival date). For the other main events, a late arrival means a shorter uration of that event (Fig. 5).

Upon arrival to sub-Saharan Africa the great snipes seem to carry no or very small fuel stores. The average mass of adult males arriving at coastal Benin in late August was $162 \mathrm{~g}$, and $155 \mathrm{~g}$ in adult males arriving coastal Gabon in September (Debayle 2003). This is similar to the body mass at the Swedish leks in May. Seven birds of unknown sex and age in Sudan in September-November weighed 145-180 g (Urban et al. 1986). A small amount of fuel is probably added before the final flight to the wintering area. Adult males in Gabon and Benin increased about $10 \mathrm{~g}$ in body mass before departure from these areas in October (Debayle 2003).

'This article is protected by copyright. All rights reserved.' 
The pattern observed with a several week long stopover in the Sahel zone, followed by another flight further south in Africa, has been described for many Palearctic migrants in both West and East Africa, and has been seen as an adaptation to make use of seasonally benign conditions created by recent rains (Pearson and Backhurst 1976, Jones 1995, Newton 2008).

\section{Main wintering grounds}

Great snipes are since long known to occur regularly over much of sub-Saharan Africa during the nonbreeding season (Glutz von Blotzheim et al. 1977, Cramp 1983, Urban et al. 1986, del Hoyo et al. 1996, Delany et al. 2009). The most recent review suggests that the final wintering grounds for most birds are "in S Democratic Republic of Congo, western and southern Tanzania, Angola, Zambia and Malawi” (Delany et al. 2009). The same source writes that the Scandinavian population is "thought to winter mainly in West Africa".

Given the vast areas reported as potential wintering grounds, it is rather astounding how relatively confined the area is where our Swedish birds were found wintering. In addition, two of the few ringing recoveries we are aware of from south of the Sahara were ringed in western Russia and found just south of the Equator, one in Congo in December and one in Democratic Republic of Congo in January (Panchenko 1985), which is very close to the general wintering area of the Swedish birds. The breeding origin of the great snipes wintering west and east of our Swedish birds remains to be revealed.

We cannot currently determine in which habitat the great snipes spend the winter, but it came as a

hig surprise to find this bird, so intimately connected to open habitats, wintering in the rain forest belt near the Equator. However, much of this area is strongly affected by human activities. Curry-Lindahl (1961), doing biological field work in the 1950's in what is now the Democratic Republic of Congo, reported: "In eastern Congo, the great snipe is found in wet, cultivated areas, that is, a habitat similar to what was previously its main habitat in Sweden. Surprisingly enough, we only found it in areas clearly affected by human activities, which is the complete opposite to the present situation in Sweden, where it is only found in remote montane areas" (our translation). 
The relatively clear raw data light curves in Africa (see Supplementary Material Fig. S4) suggest that the snipes indeed inhabit rather open habitats, and do not sit in dense rainforest.

\section{Spring migration across the Sahara}

The spring trans-Sahara flights were on average as long as the autumn flights, but the variation between individuals was much smaller, and the longest flight was $1000 \mathrm{~km}$ shorter than the longest in autumn. In spring there seems to be only one strategy adopted, that of a single long flight directly to eastern Europe. There are no indications at all of a short flight northward and subsequent stopover south of the Sahara, which would correspond to the strategy of some birds in autumn that make stopovers in northern Europe. Are feeding and flight conditions more favourable prior to the departure from the wintering grounds, or are the birds generally in better shape in late winter than in late summer?

There is a shortage of body mass data from the departure period from Africa in spring, but Debayle (2003) found average body masses of around $210 \mathrm{~g}$ in adult males in coastal Gabon in the first half of April. In addition, five birds (unknown age and sex) were reported to weigh 195-255 g in W Tanzania in May (Urban et al. 1986). The highest masses reported are similar to the highest masses reported in Scandinavia prior to autumn departure (265 g, see above).

'This article is protected by copyright. All rights reserved.' 


\section{Spring migration through eastern Europe to the breeding grounds}

The arrival of our great snipes to eastern Europe, from Italy in the west to Ukraine in the east, was concentrated to the second half of April. Counts and hunting statistics show that great snipes are fairly common in central Italy in spring, with a peak in the second half of April (Massoli-Novelli 1988a).

The birds thereafter moved relatively slowly up through eastern Europe. It is not obvious why the last part of spring migration is so slow. Feeding conditions ought to be fairly good this time of the year, so it probably does not reflect slow fuelling rates. Of course, the birds could also make use of the generous time schedule to put on extra stores for the start of the breeding period (Sandberg and Moore 1996), but we have no indications that our lekking birds in late May have any extra fuel stores (own unpubl. data). It is more likely that the birds can afford to wait and optimize the timing of arrival at the breeding grounds, which may well be the explanation to the highly synchronized arrival at the breeding grounds.

The passage by the Swedish birds through Poland, Ukraine and Belarus at the end of April and early May takes place when the local breeders there are in full breeding activity (Michał Korniluk, pers. comm.). Given that male great snipes never take part in any breeding activities after copulation, mating at leks visited on migration could be an option. Indeed, a male ringed by us in central Sweden on 23 May 2014 was trapped at an active lek in Belarus at night on 12 May 2015 (Pavel Pinchuk, pers. comm.). Future studies may show whether Scandinavian migrants on their way to the breeding grounds visit and interact with the eastern European breeding populations on a more regular basis. It clearly seems as if they would have both the time and opportunity to do so.

\section{Temporal variation of the different migration phases}

The variation in timing between individuals during the annual cycle showed the largest range, 48 days, at the arrival in the wintering grounds, and the smallest range, 7 days, at the arrival in the breeding grounds. The majority of birds were within a much more narrow time range. Although this consistency may well be the general pattern of great snipe migration, one has to remember that the data were obtained within three seasons only, only from adult males and from a smaller sample in spring than in autumn. 
The significant effects of temporal dynamics in the annual cycle of the great snipe (Fig. 5) may be caused by different individuals having consistent differences between their annual cycles, or by flexible adjustments of timings and durations by the individuals, or by a combination of between- and withinindividual variation in the annual cycle. The relative importance of within- or between-individual effects cannot be determined from the present data, due to the lack of repeated observation for the same individual. Still, the repeated data from one bird indicate that individual flexibility is likely. This bird departed early from the breeding area and made a stopover in northern Europe before the long flight to the Sahel zone in one year, but remained in the breeding area and flew directly from there to Sahel in two years (Fig. 2). Thus, individual flexibility may well contribute to the negative association between autumn stopover in Europe and departure date from the breeding area (Fig. 5). As for the remaining significant temporal effects (e.g. Fig. 6) the bird with repeated observations showed more restricted variation, making the possible importance of individual flexibility more doubtful.

The remarkably high degree of synchronization of the arrival date in the breeding area (Fig. 4) suggests that this is under strong stabilizing selection, while there seems to be room for more flexibility (within individuals) and/or alternative strategies of time schedules (between individuals) affecting the arrival time in the equatorial wintering area. The arrival date in the breeding area may be biased towards a reduced scatter because of our capturing and recapturing early in the breeding season. However, we think that this possible bias is of minor importance since captures were extended to much later dates in some years, without finding late-arriving males with geolocators.

Correlation analyses showed significant effects between adjacent time events and durations in the annual cycle, but not between more distant events. This suggests that individuals were not consistently early or late throughout the annual cycle, and that possible carry-over effects within individuals in the form of temporal advancements or delays were not propagated far into the future (Senner et al. 2014).

The dynamics of the annual cycle of the great snipe seemed to be driven by a relaxed synchronization during the autumn-winter periods, while synchronization is promoted during spring migration, in the date of departure from the wintering area and, even stronger, in the arrival date at the breeding area. This is in agreement with findings for two other migratory shorebird species that make 
marathon non-stop migratory flights, the bar-tailed godwit Limosa lapponica (Conklin et al. 2013) and the hudsonian godwit Limosa haemastica (Senner et al. 2014) tracked by geolocators throughout the annual cycle. In both species, the timing of post-breeding migration was more variable than that of pre-breeding migration. For example, hudsonian godwits varied as much as 59 days in the arrival to the main wintering area in Chile, but within years varied only as little as seven days in their departure dates (Senner et al. 2014). In the bar-tailed godwit, there was no evidence that the godwit schedules tightened across different stages of the spring migration from the winter quarters in New Zealand to the arctic breeding grounds (Conklin et al. 2013), as was observed for both the hudsonian godwits and the great snipes, but this lack of increased synchronization during spring migration may be related to the fact that the bar-tailed godwits were destined for different breeding latitudes in Alaska (Conklin et al. 2010, 2013).

The annual cycle of the great snipes consists of an intriguing pattern of temporal dynamics with significant differences in the variation of timing of different phases. The positive and negative interactions between adjacent events and durations in the annual cycle may be a result of differences in the detailed organization of the annual cycle between individuals as well as flexible rearrangements within individuals in the duration of the main stopover/stationary periods. Future studies of repeated journeys by the same individuals are needed to disentangle the relative importance of differences between and within individuals for the fascinating annual cycle dynamics of the great snipe and other migratory animals (cf. Battley 2006, Vardanis et al. 2011, Stanley et al. 2012, Conklin et al. 2010, 2013).

\section{Conservation implications}

In order to efficiently allocate conservation efforts it is important to find out during what part(s) of the annual cycle a migrant bird population is in trouble (Newton 2008). Tracking is in this respect a very useful technique as it reveals which sites the birds use throughout the year, opening up opportunities for in-depth studies on stopover and wintering ecology and for identifying potential threats.

The great snipe is a species of conservation concern and belongs to a group of species (waders) where a large fraction is declining (Delany et al. 2009). Bottlenecks throughout the annual cycle have been studied in red knots and several species of godwits, particularly well-studied waders species with similar 
migration habits (i.e. just as for great snipes migration largely consist of a few very long flights) (Gill et al. 2009, Niles et al. 2010, Hooijmeijer et al. 2013, Tomkovich et al. 2013, Senner et al. 2014). These wader species typically rely on just a few sites where large fractions of the populations congregate. This turns out a risky strategy, not least when these few sites are threatened by exploitation and alternative sites may be scarce, as for example in the Yellow Sea area (Rogers et al. 2010, Yang et al. 2011) and the Dutch Waddensea (Rahhimberdiev et al. 2015). Great snipes, however, do not seem to concentrate at any particular sites outside the breeding season (Delany et al. 2009). This implies that favourable habitats are more widespread and that there are still many good-enough sites available to support their extreme migration strategy. Nevertheless, we still need to identify in which habitats and areas the main fuelling for the long flights takes place, to ensure that there are no imminent threats there, although more detailed (accurate) tracking data is required in order to achieve this. Further, the importance of the breeding sites in eastern Europe as stopover, and possibly mating, sites for Swedish great snipes needs more attention.

\section{Acknowledgements}

We are most grateful to Michel Devort for translating and making available the wealth of data on great snipes he collected in sub-Saharan Africa. We thank Michel Devort, Edouard Debayle, Yves Ferrand, Patrice Février and Włodzimierz Meissner for help with literature and Ulf Ottosson and Pavel Pinchuk for providing unpublished information. Ernesto Alvarado, Hanna Bahlenberg, Lotta Berg, Roeland Bom, Mikael Carlsson, Per Gustafsson, Peter Jonsson, Sofia Jonsson, Meera Lee Sethi, Anna Polotnicka, Anders Tengholm, Erik Tengholm, Johan Tengholm, Jennie Wadman, Bernadetta Wolczuk and Magda Zadrag assisted during field work. Two anonymous reviewers contributed valuable comments on the manuscript. Financial support was received from the Swedish Research Council (to TA) and the Centre for Animal Movement Research at Lund University (CAnMove, Linnaeus grant 349-2007-8690). The work was carried out under permit from the Lund/Malmö Ethical Committee for Animal Experiments (M112-09, M27-10, M470-12, M33-13).

'This article is protected by copyright. All rights reserved.' 


\section{References}

Alerstam, T. 1990. Bird migration. - Cambridge University Press.

Alerstam, T. 2006. Conflicting evidence about long-distance animal navigation. - Science 313: 791-794.

ArtDatabanken 2015. Rödlistade arter i Sverige 2015. - ArtDatabanken SLU, Uppsala. [In Swedish]

Bakken V., Runde, O. and Tjørve, E. 2003. Norwegian Bird Ringing Atlas (Volume 1 Divers-Auks). Stavanger Museum.

Barth, J. B. 1881. Norges fuglevildt og jagten paa samme. - Gyldendalske Boghandelns Forlag, Copenhagen. [In Norwegian]

Battley, P. F. 2006. Consistent annual schedules in a migratory shorebird. - Biol. Lett. 2: 517-520.

Berthold, P., Nowak, E. and Querner, U. 1992. Satelliten-Telemetrie beim Weisstorch (Ciconia ciconia) auf den Wegzug - eine Pilotstudie. - J. Orn. 133: 155-163.

Bønløkke, J., Madsen, J.J., Thorup, K., Pedersen, K.T., Bjerrum, M. and Rahbek, C. 2006. The Danish Bird Migration Atlas. - Rhodos, Humlebæk.

Conklin, J. R., Battley, P. F., Potter, M. A. and Fox, J. W. 2010. Breeding latitude drives individual schedules in a trans-hemispheric migrant bird. - Nature Comm. 1: 67.

Conklin, J. R. Battley, P. F. and Potter, M. A. 2013. Absolute consistency: individual versus population variation in annual-cycle schedules of a long-distance migrant bird. - PLoS ONE 8(1): e54535.

Cramp, S. and Simmons, K. E. L. (eds) 1983. The birds of the Western Palearctic. Vol. 3. - Oxford University Press.

Curry-Lindahl, K. 1961. Flyttfåglarnas tropiska vinterhem. - Folket i bild, Stockholm. [In Swedish]

Debayle, E. J. M. 2003. Contribution to the knowledge of the Great Snipe, Gallinago media: a study of the wintering in Africa, from a sample of 10 years. - Vet. Dr. thesis, Ecole Nationale Veterinaire, Toulouse (In French).

Delany, S., Scott, D., Dodan, T. and Stroud, D. (eds). 2009. An atlas of wader populations in Africa and western Eurasia. - Wetlands International, Wageningen, The Netherlands.

del Hoyo, J., Elliott, A. and Sargatal, J. (eds) 1996. Handbook of the birds of the World. Vol 3. Hoatzin to Auks. - Lynx Edicions, Barcelona.

Devort, M. and Paloc, R. 1992. About the moults of the Great Snipe (G. media) in Africa. Contribution a l'étude des migrations et de la biologie des bécassines. - Paris: C.I.C.B.: 53-57.

Ekblom, R. and Carlsson, P. 2007. An estimate of the Great Snipe Gallinago media population in Sweden based on recent surveys at Ånnsjön and Storlien. - Ornis Svecica 17: 37-47.

Ekblom, R., Saether, S., Fiske, P., Kålås, J. and Höglund, J. 2010. Balancing selection, sexual selection and geographic structure in MHC genes of Great Snipe.- Genetica, 138: 453-461.

Ekstrom, P. A. 2004. An advance in geolocation by light. - Mem. Natl. Inst. Polar Res., Spec. Issue 58: 210-226.

Elgood, J. H. 1994. Birds of Nigeria. - British Ornithologists' Union, Tring.

Fransson, T., Österblom, H. and Hall-Karlsson, S. 2008. Swedish Bird Ringing Atlas, Vol. 2, GrousesWoodpeckers. - Naturhistoriska Riksmuséet, Stockholm.

Gill, R. E. Jr, Tibbitts, T. L., Douglas, D. C., Handel, C. M., Mulcahy, D. M., Gottschalck, J. C., Warnock, N., McCaffery, B. J., Battley, P. F. and Piersma, T. 2009. Extreme endurance flights by landbirds crossing the Pacific Ocean: ecological corridor rather than barrier? - Proc. R. Soc. Lond. B 276: $447-458$.

Glutz von Blotzheim, U. N., Bauer, K. M. and Bezzel, E. (eds) 1977. Handbuch der Vögel Mitteleuropas. Band 7. Charadriformes (2. teil). - Akademische Verlagsgesellschaft, Wiesbaden.

Hedenström, A. 2010. Extreme Endurance Migration: What Is the Limit to Non-Stop Flight? - PLoS Biol 8(5): e1000362.

Hill, C. and Braun, M. J. 2001. Geolocation by light level - the next step: latitude. - In: Sibert, J. R. and Nielsen, J. (eds), Electronic Tagging and Tracking in Marine Fisheries. Kluwer Academic Publishers, pp. 315-330.

Hooijmeijer, J. C. E. W., Senner, N. R., Tibbitts, T. L., Gill, R. E., Jr, Douglas, D. C., Bruinzeel, L. W., Wymenga, E. and Piersma, T. 2013. Post-breeding migration of Dutch-breeding black-tailed godwits: timing, routes, use of stopovers, and nonbreeding distributions. - Ardea 101: 141-152.

Höglund, J., Kålås, J.A. and Løfaldli, L. 1990. Sexual dimorphism in the lekking Great Snipe. - Ornis Scand. 21: 1-6.

Johnson, O. W., Fielding, L., Fox, J. W., Gold, R. S., Goodwill, R. H. and Johnson, P. M. 2011. Tracking the migrations of Pacific Golden-Plovers (Pluvialis fulva) between Hawaii and Alaska: New insight

'This article is protected by copyright. All rights reserved.' 
on flight performance, breeding ground destinations, and nesting from birds carrying light level geolocators. - Wader Study Group Bull. 118: 26-31.

Jones, P. 1995. Migration strategies of palearctic passerines in Africa. - Isr. J. Zool. 41: 393-406.

Jouventin, P. and Weimerskirch, H. 1990. Satellite tracking of wandering albatrosses. - Nature 343: 746748.

Kjellén, N., Hake, M. and Alerstam, T. 1997. Strategies of two Ospreys Pandion haliaetus migrating between Sweden and tropical Africa as revealed by satellite tracking. - J. Avian Biol. 28: 15-23.

Klaassen, R. H. G., Alerstam, T., Carlsson, P., Fox, J. W. and Lindström, A. 2011. Great flights by Great Snipes: long and fast non-stop migration over benign habitats. - Biol. Lett. 7:833-835.

Kolthoff, G. 1901. Ur djurens lif. - Fr. Skoglunds, Stockholm. [In Swedish]

Lindblad, J. W. 1863. Dubbla Beckasinen. - Sv. Jägarförb. Nya Tidskr. 1:15-33. [In Swedish].

Lindström, A., Gill, R. E. Jr, Jamieson, S. E., McCaffery, B., Wennerberg, L., Wikelski, M. and Klaassen, M. 2011. A puzzling migratory detour: are fueling conditions in Alaska driving the movement of juvenile sharp-tailed sandpipers? - Condor 113: 129-139.

Lisovski, S., Hewson, C. M., Klaassen, R. H. G., Korner-Nievergelt, F., Kristensen, M. W. and Hahn, S. 2012. Geolocation by light: accuracy and precision affected by environmental factors. - Methods Ecol. Evol. 3: 603-612.

Massoli-Novelli, R. 1988a. Migration, ringing recoveries and some bag statistics of Common, Great and Jack Snipe in Italy. - Proc. $3^{\text {rd }}$ European Woodcock and Snipe workshop, Paris: 16-19.

Massoli-Novelli, R. 1988b. Status and habitat of Great Snipe in Ethiopia and its movements in Africa. Proc. $3^{\text {rd }}$ European Woodcock and Snipe workshop, Paris: 12-15.

McKinnon, E. A., Fraser, K. C. and Stutchbury, B. J. M. 2013. New discoveries in landbird migration using geolocators, and a flight plan for the future. - Auk 130: 211-222.

McLaren, J.D., Shamoun-Baranes, J., Dokter, A.M., Klaassen, R. H. G., Bouten, W. 2014. Optimal orientation in flows: providing a benchmark for animal movement strategies. - J. R. Soc. Interface 11: 20140588.

Meltofte, H. 1993. Vadefugletraekket gennem Danmark. - Dansk Orn. For. Tidssk. 87: 1-180.

Meyburg, B.-U., Scheller, W. and Meyburg, C. 1995. Zug und Überwinterung des Schreiadlers Aquila pomarina: Satellitentelemetrische Untersuchungen. - J. Orn. 136: 401-422.

Minton, C., Gosbell, K., Johns, P., Fox, J. W. and Afanasyev, V. 2010. Initial results from light level geolocator trials on Ruddy Turnstones Arenaria interpres reveal unexpected migration route. Wader Study Group Bull. 117, 9-14.

Newton, I. 2008. The migration ecology of birds. - Academic Press, London.

Niles, L. J., Burger, J., Porter, R. R., Dey, A. D., Minton, C. D. T., Gonzalez, P. M., Baker, A. J., Fox, J. W. and Gordon, C. 2010. First results using light level geolocators to track Red Knots in the Western Hemisphere show rapid and long intercontinental flights and new details of migration pathways. Wader Study Group Bull. 117, 123-130.

Nilsson, S. 1858 Skandinavisk fauna. Foglarna. Andra bandet. - Gleerups, Lund. [In Swedish]

Panchenko, V. G. 1985. Great Snipe - Gallinago media Lath. In: Viksne J.A. and Michelson H.A. (eds) Migration of birds of Eastern Europe and Northern Asia. - Nauka, Moscow, pp. 235-239. [In Russian].

'earson, D. J. and Backhurst, G. C. 1976. The southward migration of Palearctic birds over Ngulia, Kenya. - Ibis 118: 78-105.

Pennycuick, C. J. 1975. Mechanics of flight. - In: Farner, D. S. and King, J. R. (eds), Avian Biology, vol. V. Academic Press, New York, pp. 1-75.

Pütz, K. 2002. Spatial and temporal variability in the foraging areas of breeding king penguins. - Condor 104: 528-538.

Rakhimberdiev, E., van den Hout, P. J., Brugge, M., Spaans, B. and Piersma, T. 2015. Seasonal mortality and sequential density dependence in a migratory bird. - J. Avian Biol. 46: 332-341.

Rogers, D. I., Yang, H.-Y., Hassell, C. J., et al. (2010). Red Knots (Calidris canutus piersmai and C. c. rogersi) depend on a small threatened staging area in Bohai Bay, China. - Emu 110: 307-315.

Salvan, J. 1968. Contribution a l'étude des Oiseaux du Chad. - L'Oiseau et al RFO 38: 3-80.

Sandberg, R. and Moore, F. R. 1996. Fat Stores and Arrival on the Breeding Grounds: Reproductive Consequences for Passerine Migrants. - Oikos 77: 577-581.

Saurola, P., Valkama, J. and Velmala, W. 2013. The Finnish Bird Ringing atlas. Volume 1. - Finnish Museum of Natural History, Helsinki.

'This article is protected by copyright. All rights reserved.' 
Senner, N. R., Hochachka, W. M, Fox, J. W., Afanasyev, V. 2014. An exception to the rule: carry-over effects do not accumulate in a long-distance migratory bird. - PLoS ONE 9(2): e86588.

Shamoun-Baranes, J., Leyrer, J., van Loon, E., Bocher, P., Robin, F., Meunier, F. and Piersma, T. 2010. Stochastic atmospheric assistance and the use of emergency staging sites by migrants. - Proc. R. Soc. Lond. B 277: 1505-1511.

SOF. 2002. Sveriges fåglar: aktuell översikt över deras utbredning, numerär och flyttning. - Vår Fågelvärld, suppl. 36. [In Swedish]

Sokal, R. R. and Rohlf, F. J. 1995. Biometry: the principles and practice of statistics in biological research. - W. H. Freeman, New York.

Stanley, C. Q., MacPherson, M., Fraser, K. C., McKinnon, E. A. and Stutchbury, B. J. M. 2012. Repeat tracking of individual songbirds reveals consistent migration timing but flexibility in route. - PLoS One. 7:e40688.

Stutchbury, B. J. M., Tarof, S. A., Done, T., Gow, E., Kramer, P. M., Tautin, J., Fox, J. W. and Afanasyev, V. 2009. Tracking long-distance songbird migration by using geolocators. - Science 323: 896.

Tomkovich, P. S., Porter, R. R., Loktionov, E. Y. and Niles, L. J. 2013. Pathways and staging areas of Red Knots Calidris canutus rogersi breeding in southern Chukotka, Far Eastern Russia. - Wader Study Group Bull. 120:181-193.

Urban, E. K., Fry, C. H. and Keith, S. (eds). 1986. Birds of Africa. Vol. II. - Academic Press, London.

Vardanis, Y., Klaassen, R. H. G., Strandberg, R. and Alerstam, T. 2011. Individuality in bird migration: routes and timing. - Biol. Lett. 7: 502-505.

Yang, H.-Y., Chen, B., Barter, M., et al. (2011). Impacts of tidal land reclamation in Bohai Bay, China: ongoing losses of critical Yellow Sea waterbird staging and wintering sites. - Bird Conservation International 21: 241-259. 


\section{Table Legend}

Table 1. The annual number of geolocators deployed on male great snipes in 2009-2013, and the return rate of these birds one or more years later ( 20 out of 22 returns were recaptured the first year after deployment). For comparison we also show the number of handled birds (receiving a ring, or already wearing a ring when captured) that were not given a geolocator, and the return rate of these birds.

\begin{tabular}{|c|c|c|c|c|c|c|}
\hline \multirow[b]{2}{*}{ Year } & \multicolumn{3}{|c|}{ Males with geolocators } & \multicolumn{3}{|c|}{ Males with metal ring only } \\
\hline & \# deployed & \# returning & $\begin{array}{l}\% \\
\text { returning }\end{array}$ & \# handled & \# returning & $\%$ returning \\
\hline 2009 & 10 & 3 & 30 & 10 & 3 & 30 \\
\hline 2010 & $10^{1}$ & 0 & 0 & $23^{2}$ & 7 & 30 \\
\hline 2011 & 20 & $11^{3}$ & 55 & 5 & 4 & 80 \\
\hline 2012 & 15 & $(3)^{4}$ & (20) & 21 & 4 & 19 \\
\hline 2013 & 15 & 8 & 53 & 19 & 6 & 32 \\
\hline
\end{tabular}

${ }^{1}$ All birds receiving a geolocator were caught at one lek. This lek was not present in 2011, and none of the geolocator birds was recaptured. ${ }^{2}$ Nineteen of these males were ringed at other leks than the focal lek (see $\left.{ }^{1}\right) .{ }^{3}$ One of these birds was recovered first in 2013, carrying $1 \frac{1 / 2}{2}$ year of data, and another was first retrieved in 2014, carrying no data at all. ${ }^{4}$ Although these 3 birds did return, they had all lost their geolocator.

'This article is protected by copyright. All rights reserved.' 


\section{Figure Legends}

Figure 1. The autumn (a) and spring (b) migration of great snipes travelling between the breeding site in Sweden $\left(63^{\circ} \mathrm{N}, 12^{\circ} \mathrm{E}\right)$ and their winter quarters in central Africa. Green dots show the breeding site according to the light geolocators, orange and yellow dots show stopover sites in Europe/northern Africa and sub-Saharan Africa, respectively, and blue dots the final wintering sites. Red solid lines mark the non-stop flights, and grey thin lines show shorter flights.
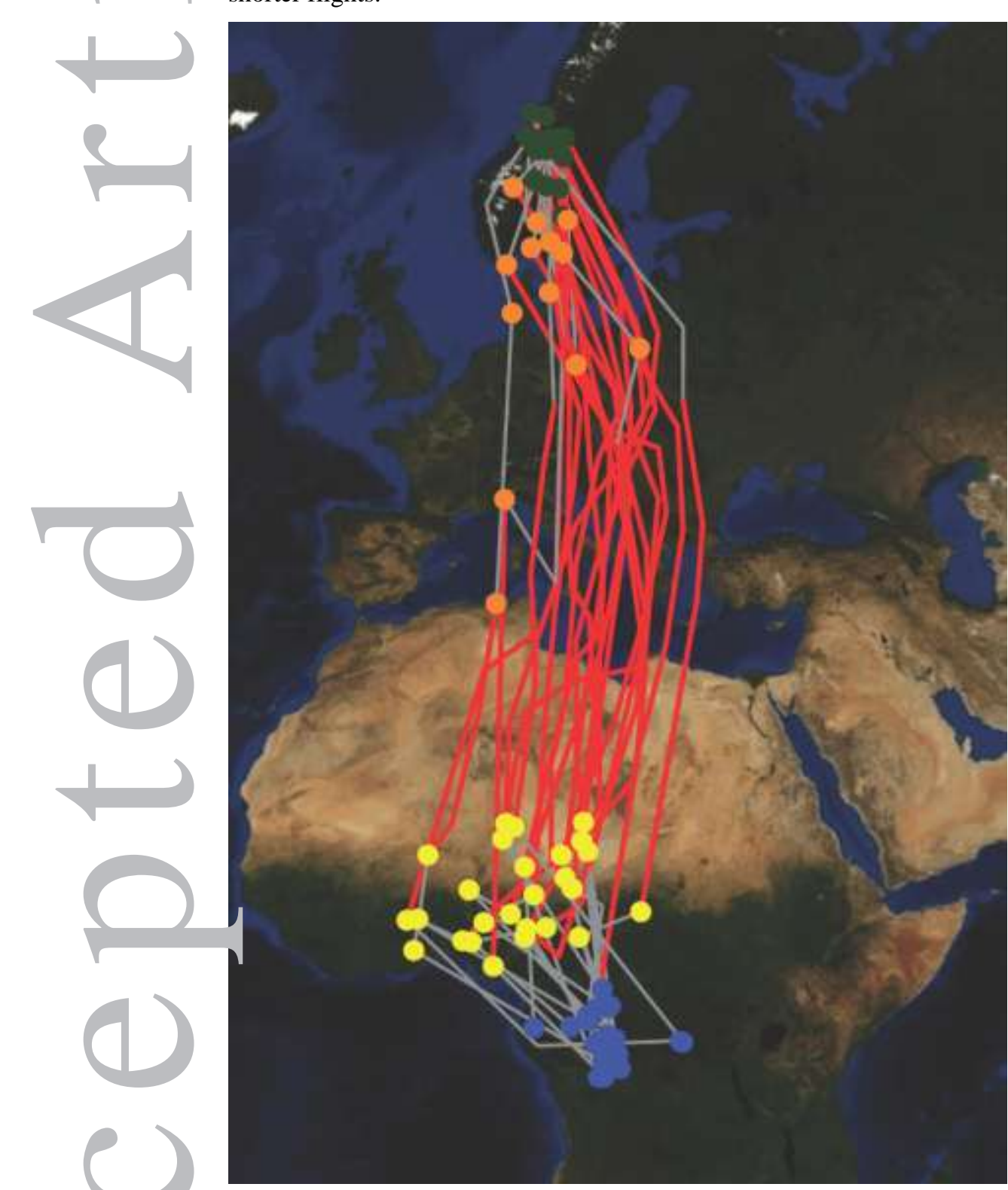

'This article is protected by copyright. All rights reserved.' 

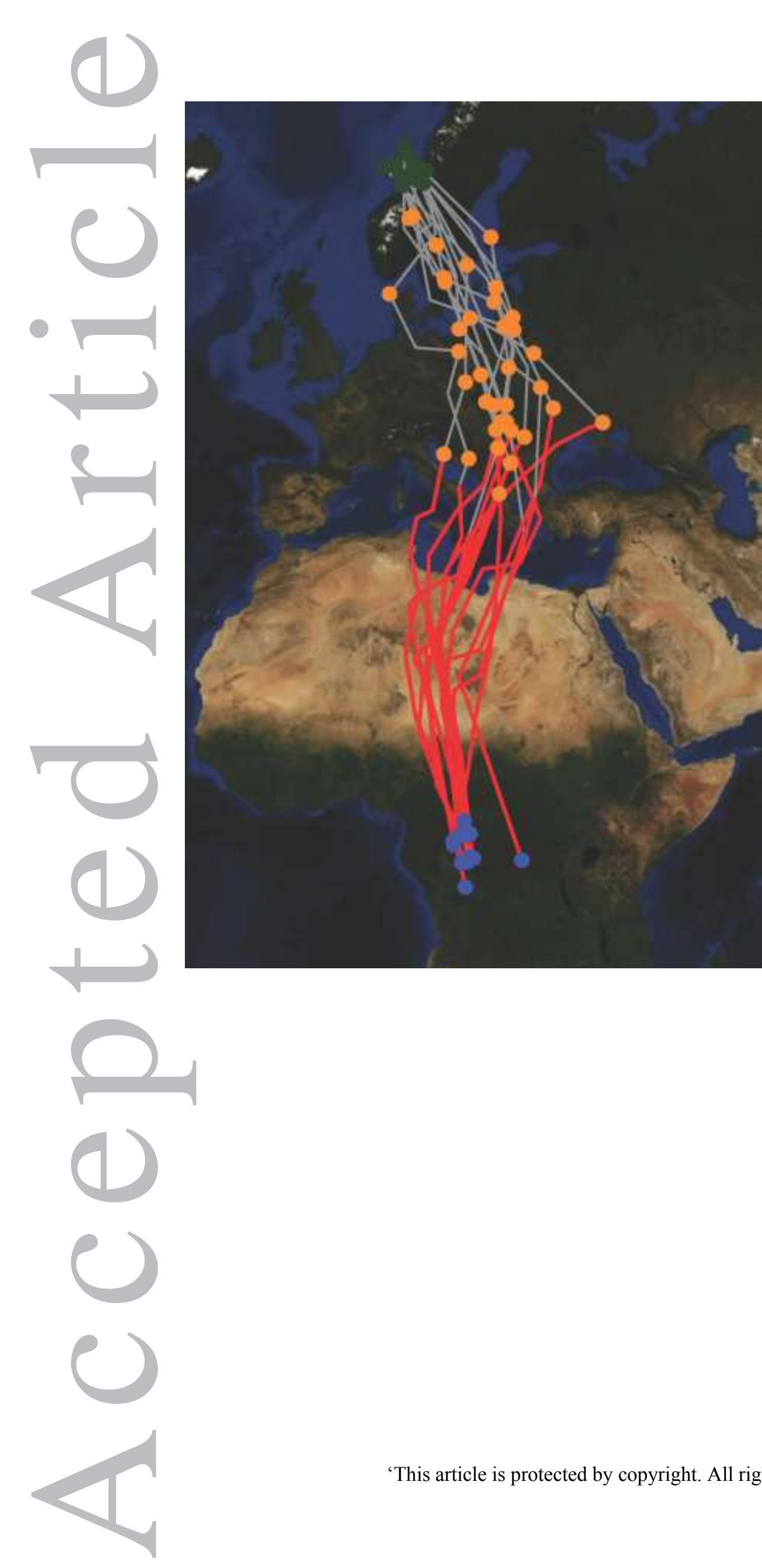

'This article is protected by copyright. All rights reserved.' 

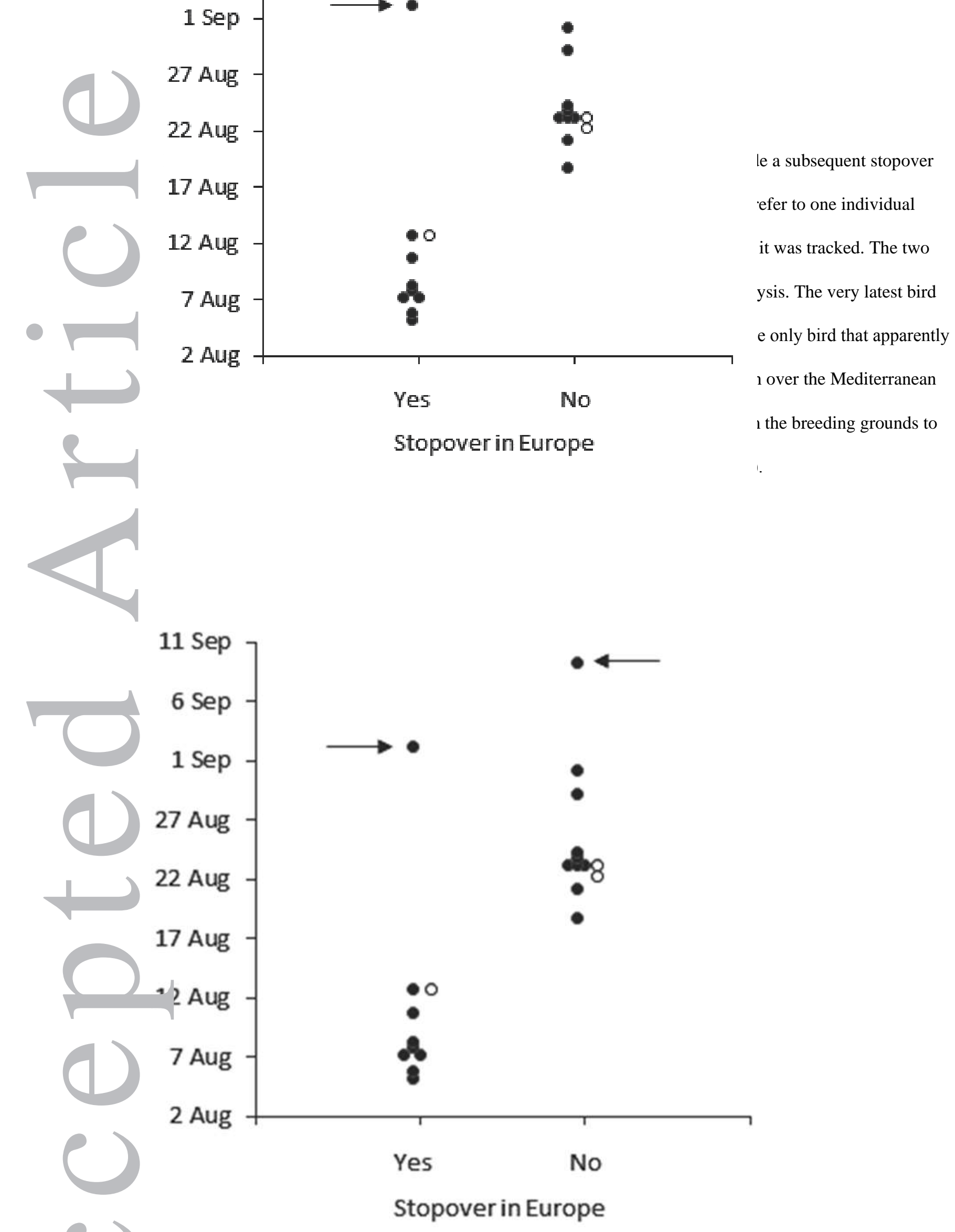

'This article is protected by copyright. All rights reserved.' 
Figure 3. The proportion of 18 great snipes that was present on stopover in sub-Saharan Africa on a given date. Data are from three different years.

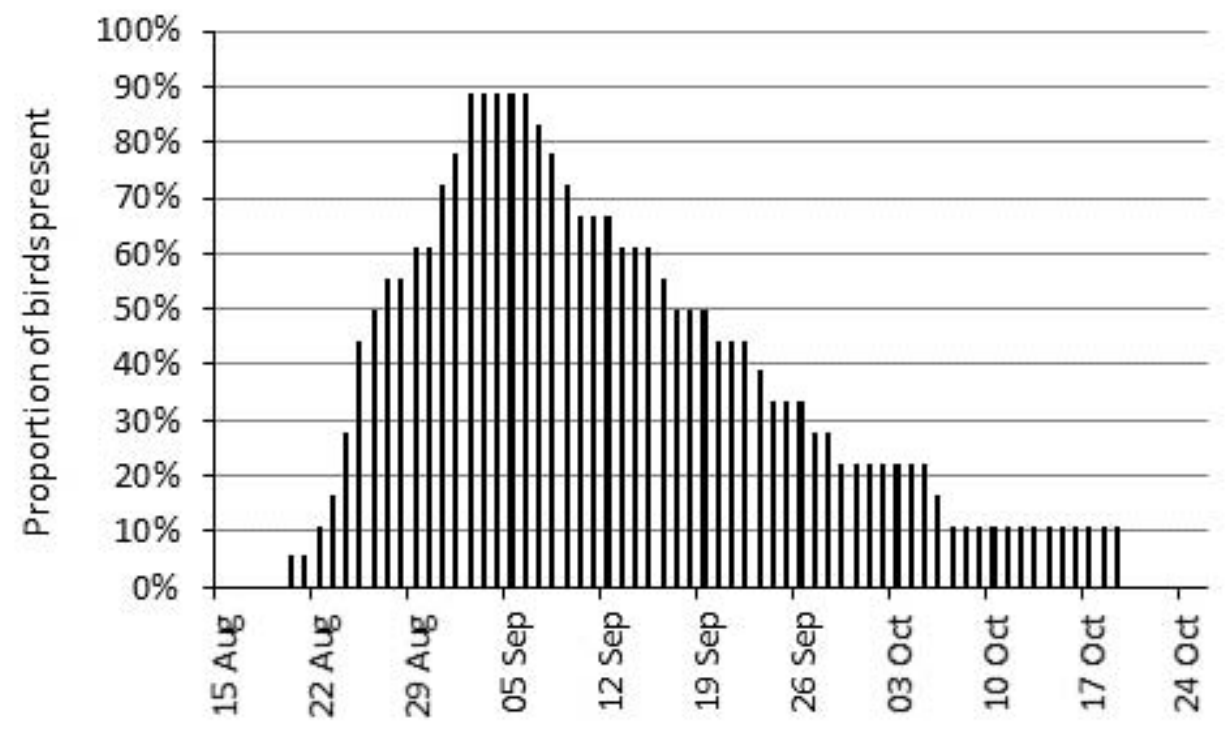

'This article is protected by copyright. All rights reserved.' 
Figure 4. Variation in timing of five key events in the annual cycle of the great snipe. The bars show the standard deviation (SD) and range in dates for each of the five events. Significant changes in SD from the preceding event are indicated $(* * \mathrm{p}<0.01)$.

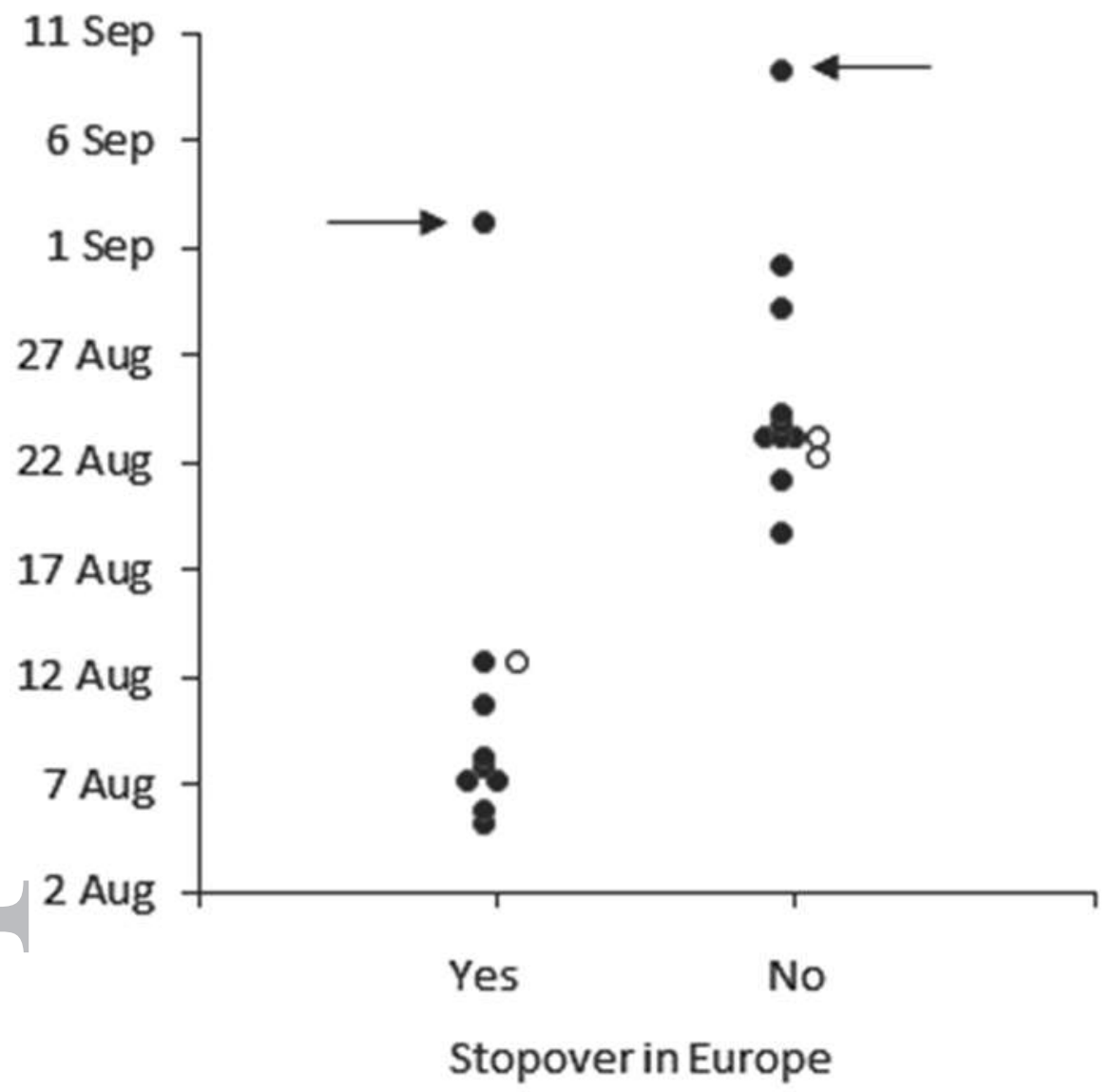

'This article is protected by copyright. All rights reserved.' 
Figure 5. The relationships between important dates and durations in the annual cycle of the great snipes.

Succeeding timing events are shown in circles and succeeding stationary periods in squares. Figures show
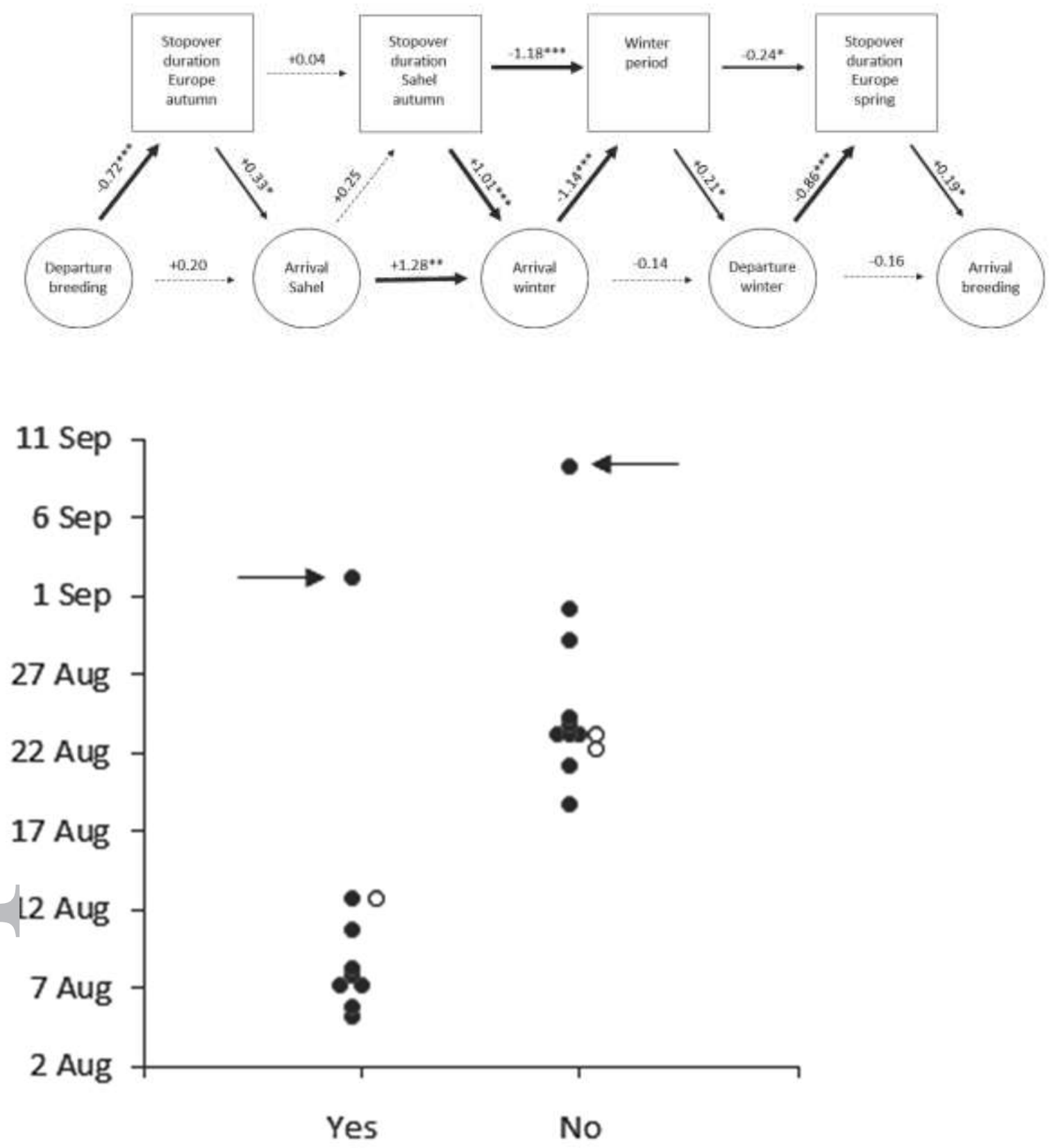

Stopover in Europe

'This article is protected by copyright. All rights reserved.' 
Figure 6. The relationship between the timing of different key stages of great snipe migration. The date of arrival in the wintering area in relation to stopover duration in Sahel (a), the duration of the winter period in relation to date of arrival in wintering area (b), and the duration of spring stopover in Europe in relation to date of departure from wintering area (c). Dates (day number) 110 and 270 are equal to 20 April and 27 September, respectively. Open symbols refer to bird \#5116319 with data from three (a) or two (b and c) migration cycles.
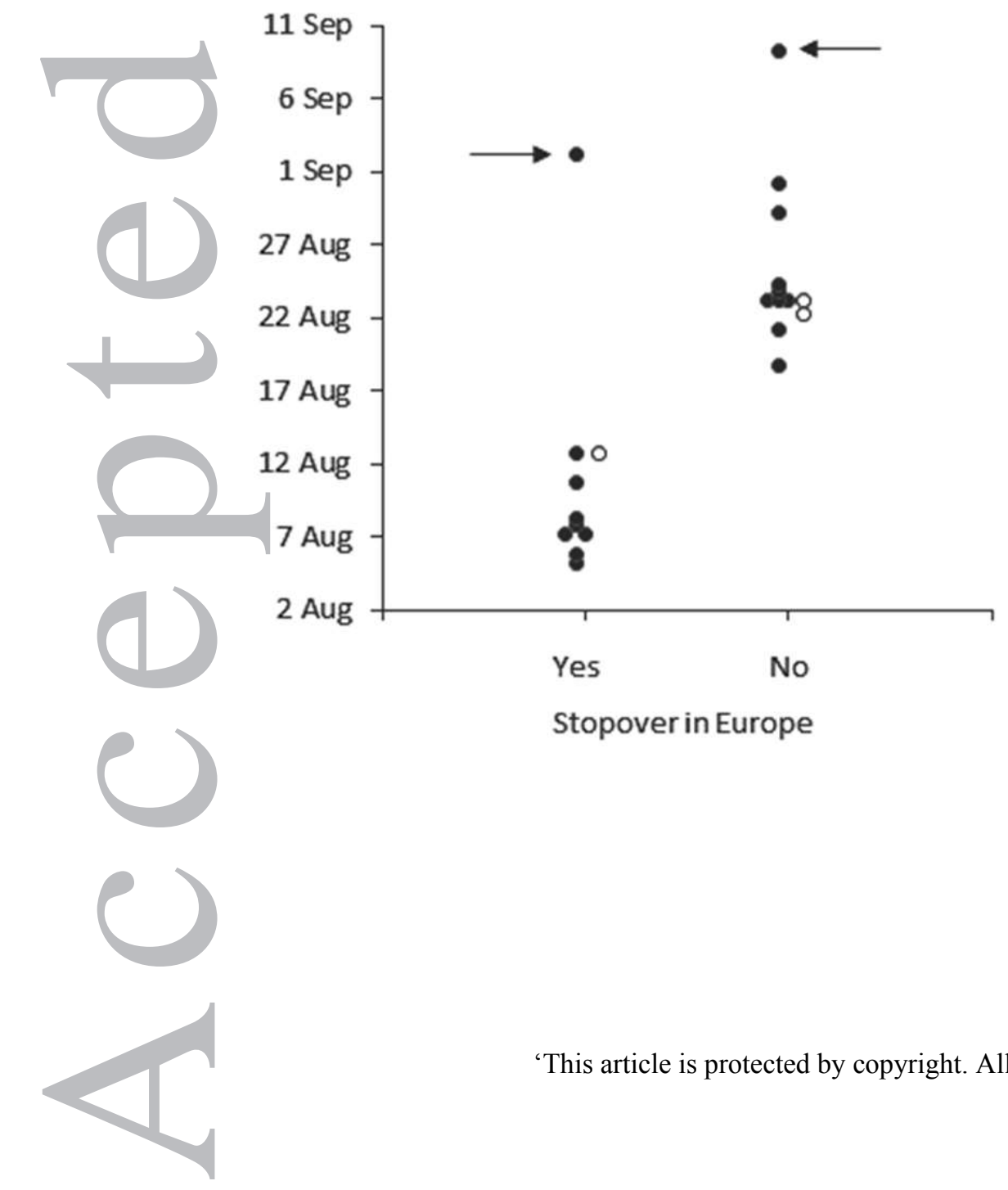

'This article is protected by copyright. All rights reserved.' 


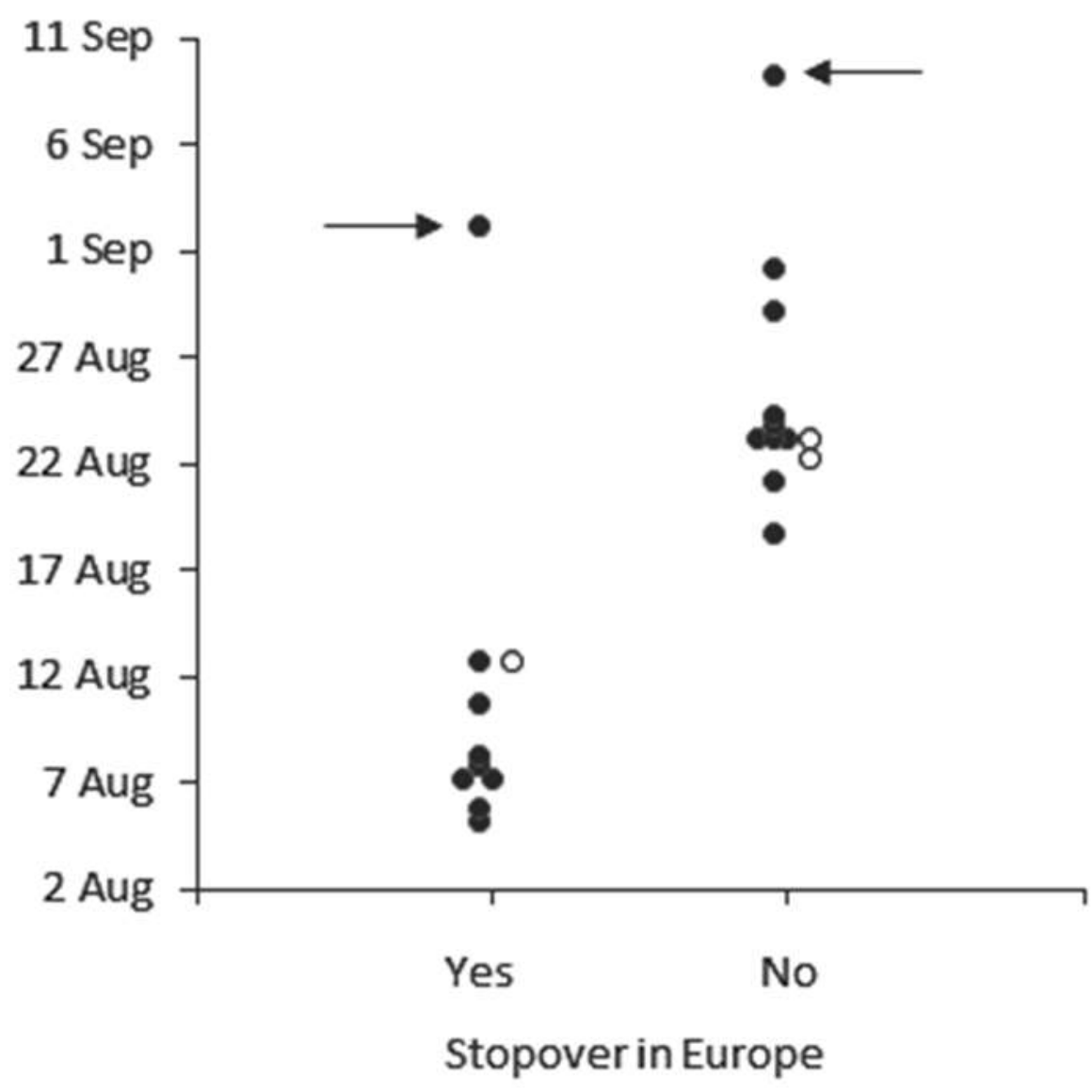




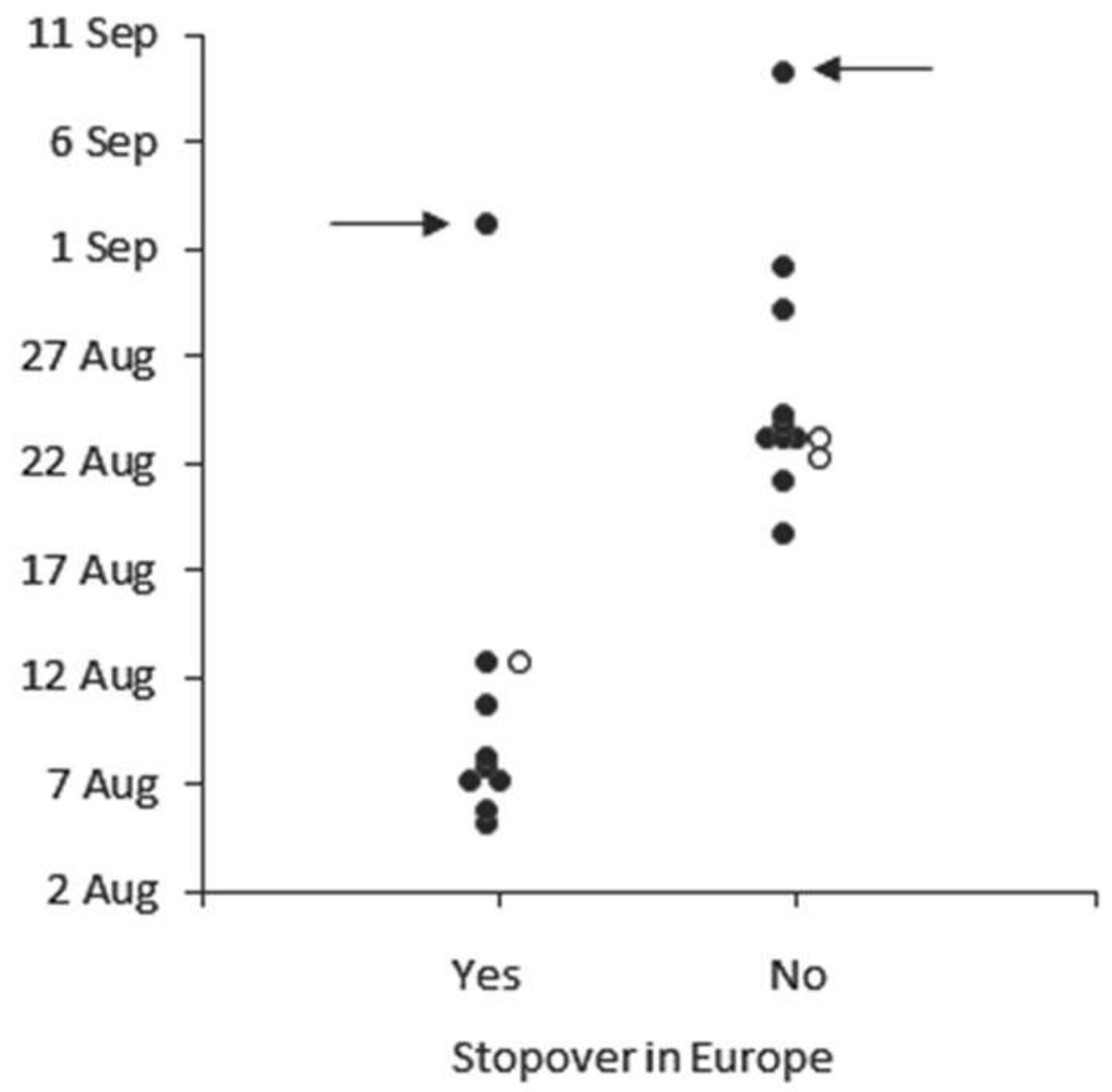

'This article is protected by copyright. All rights reserved.' 